\title{
Kinetic analysis of the transient phase and steady state of open multicyclic enzyme cascades
}

\author{
Ramón Varón ${ }^{1 凶}$, Bent H. Havsteen ${ }^{2}$, Edelmira Valero ${ }^{1}$, \\ Milagros Molina-Alarcón ${ }^{3}$, Francisco García-Cánovas ${ }^{4}$ \\ and Manuela García-Moreno ${ }^{1}$
}

${ }^{1}$ Departamento de Química Física, Escuela Politécnica Superior, Universidad de Castilla-La Mancha, Albacete, Spain; ${ }^{2}$ Department of Biochemistry, School of Medicine, University of Kiel, Kiel, Germany; ${ }^{3}$ Departamento de Enfermería, Escuela Universitaria de Enfermería, Universidad de Castilla-La Mancha, Albacete, Spain;

${ }^{4}$ Departamento de Bioquímica y Biología Molecular A, Facultad de Biología, Universidad de Murcia, Murcia, Spain; ${ }_{e}$-mail: ramon.varon.@uclm.es

Received: 14 October, 2004; revised: 08 March, 2005; accepted: 20 May, 2005

available on-line: 05 June, 2005

\begin{abstract}
This paper presents a kinetic analysis of the whole reaction course, i.e. of both the transient phase and the steady state, of open multicyclic enzyme cascade systems. Equations for fractional modifications are obtained which are valid for the whole reaction course. The steady state expressions for the fractional modifications were derived from the latter equations since they are not restricted to the condition of rapid equilibrium. Finally, the validity of our results is discussed and tested by numerical integration. Apart from the intrinsic value of knowing the kinetic behaviour of any of the species involved in any open multicyclic enzyme cascade, the kinetic analysis presented here can be the basis of future contributions concerning open multicyclic enzyme cascades which require the knowledge of their time course equations (e.g. evaluation of the time needed to reach the steady state, suggestion of kinetic data analysis, etc.), analogous to those already carried out for open bicyclic cascades.
\end{abstract}

Keywords: enzyme kinetics, multicyclic cascades, transient phase, steady state, fractional modification

Enzyme cascades are ubiquitous in biological systems. They play an important role in the regulation of many physiological processes, e.g. regulation of metabolism, repair of lesions, protection against infectants, regulation of neurotransmitter receptor function and of the efficiency of synaptic transmission, or determination of the balance between cell activation and cell death. The special significance of enzyme cascades is their ability to impose upper and lower boundaries on the rates of a biological process. Besides, the abundance of the design features in enzyme cascades provides many possibilities of response and adaptation to environmental cues and challenges. Such cascades are therefore essential to the success of evolutionary systems. The complicated structure of many enzyme cascades renders the kinetic analysis difficult. However, it is a prerequisite for the understanding of biological regulation at a high level.

Enzyme cascades may be classified into noncyclic and cyclic ones. The non-cyclic cascades are irreversible and unidirectional and involve activation of zymogens. A kinetic analysis of a general model of non-cyclic cascades has already been carried out (Havsteen et al., 1993). Cyclic cascades are a common and important type of enzyme cascades which operate by allosterically regulated chemical modification/demodification of the active site of key metabolic enzymes. Some examples of cyclic cascades are the cascade involved in the modulation of glycogen synthase and glycogen phosphorylase activity (Krebs, 1972; Chock et al., 1980; Edstrom et al., 1990; Cárdenas \& Goldbeter, 1996; Schulz, 1998; Gall et al., 2000; Hanashiro \& Roach, 2002; de Paula et al., 2002; Rozi \& Jia, 2003), the one involved in the regulation of Escherichia coli glutamine synthetase (Stadtman et al., 1976; Chock et al., 1990; Stadtman, 1990; 2001; Jiang et al., 1998; Mutalik et al., 2003), the G-protein cascade mediating phototransduction (Lamb, 1996), the mitogen-activated protein kinase cascades in Saccharomyces cerevisae (Gustin et al., 1998; Pomerance et al., 2000) and Xenopus lae- 
vis (Ferrell \& Machleder, 1998), the genetic cascades such as the E. coli flagellar regulatory cascade (Kalir et al., 2001; Thattai \& van Oudenaarden, 2002) or the cascade involved in the regulatory mechanism of inflammation and autoimmunity (Van den Steen et al., 1998). Another type of cyclic cascades involved in metabolic regulation are substrate cycles, where a target metabolite is reversibly interconverted into another chemical species by two different enzymes coupled in the opposite directions (Newsholme et al., 1984). The kinetics of substrate cycling are well known, both in the steady state (Passonneau \& Lowry, 1978) and in the transient phase (Valero \& García-Carmona, 1996), allowing these systems to be applied to the quantitative determination of low levels of a metabolite or an enzyme activity (Passonneau \& Lowry, 1993; Valero et al., 1997; 2000).

Concerning enzyme cascades, the steady state kinetics of monocyclic (Stadtman \& Chock, 1977; Goldbeter \& Koshland, 1987; 1990; Cárdenas \& Cornish-Bowden, 1989; 1990; Szedlacsek et al., 1992) and multicyclic (Chock \& Stadtman, 1977; Stadtman \& Chock, 1979) systems has been analysed under some simplifying conditions that facilitate the derivation of the steady state kinetic equations. Besides, a complete kinetic analysis for both the transient phase and the steady state of monocyclic (Varón \& Havsteen, 1990) as well as open and closed bicyclic cascades (Varón et al., 1994a; 1994b) has been performed. However, a complete analysis of multicyclic enzyme systems, valid from the begin of the process, i.e. for both the steady state and the transient phase, remains to be carried out yet. Only simulated progress curves of uni-, bi- and tricyclic cascades obtained under severe assumptions were obtained (Stadtman \& Chock, 1979), but no analytical time course equations for any of the species involved have been derived yet.

From the above it is clear that there are gaps in the kinetic analysis of multicyclic cascades. The steady state kinetic behaviour under different simplifying conditions is known (Chock \& Stadtman, 1980), but there is no information about the way the system reaches this steady state, i.e. about the transient phase of the reaction. Analysis of the transient phase of multicyclic enzyme cascades is biologically important for the following reasons:

1) The transient phase kinetic analysis is the first step to establishing the time course of the different regulatory properties of a system and not only in the steady state of the reaction. Moreover, emerging from the transient phase equations of the cascades, studies could be carried out introducing new regulatory parameters allowing one to estimate the time needed by the system to reach the steady state or the time elapsed to generate a biochemical response to any primary stimuli, as already propose by us for mono- and bicyclic enzyme cascades
(Varón \& Havsteen, 1990; Varón et al., 1994a; 1994b). This parameter is important, because a cascade of a high steady state sensitivity, but a long transient time may, in real time, behave like a low sensitivity system and, conversely, a cascade of a moderate steady state sensitivity could, in real time, displays a considerable sensitivity, if it has a short transient phase.

2) From the transient phase kinetic analysis an experimental design and a kinetic data analysis can be suggested which allow the evaluation of more kinetic parameters than those based on the steady state only. This has already been carried out for monocyclic and bicyclic cascades (Varón \& Havsteen, 1990; Varón et al., 1994a; 1994b).

3) From the transient phase equations those corresponding to the steady state can be obtained immediately.

4) Although most of the cyclic enzyme cascades known are either bicyclic (Stadtman \& Chock, 1979; Chock \& Stadtman, 1980; Cárdenas \& CornishBowden, 1989; Varón et al., 1994a; 1994b) or tricyclic (Mutalik et al., 2004), we think that in the future multicyclic cascades involving more cycles will be reported and the analysis presented here could be a useful tool for the workers in this field and, of course, it can be applied, as a particular case, to any of the open multicyclic enzyme cascades actually known which fits the model.

5) Finally, from a general open multicyclic cascade containing $\mathrm{N}$-cycles a better appreciation of the relationship between the number of cycles in an open enzyme cascade and its regulatory properties can be obtained (Stadtman \& Chock, 1979).

Therefore, the biological objectives of this paper are:

a) To present a general kinetic analysis of open multicyclic cascade enzyme systems covering the whole course of the reaction, assuming certain conditions that render possible the derivation of explicit analytical equations that provide the transient phase equations for any form of the interconvertible enzymes involved in the model. From this kinetic analysis any of the tasks mentioned in points 1) and 2) above can be undertaken.

b) To obtain the kinetic equations for the steady state as a particular case of the corresponding solution for the transient phase when time assumes sufficiently high values.

c) To apply the results to some particular cases of open cyclic cascades.

d) To discuss the validity of our kinetic analysis and to check the quality of our results by comparison with those obtained by numerical integration using a specific software for enzyme reactions previously developed by us (García-Sevilla et al., 2000) which allows the simulation of the kinetic behaviour of enzyme systems (e.g. any open multi- 
cyclic cascade) for any set of values of the rate constants and initial concentrations.

\section{MATERIALS AND METHODS}

Simulated progress curves were obtained by numerical solution of the non-linear set of differential equations (B2) in Appendix $\mathrm{B}^{1}$, using arbitrary sets of rate constants and initial concentration values. This numerical solution was found by the Runge-Kutta-Fehlberg algorithm (Fehlberg, 1970; Burden \& Faires, 1985) using a computer program implemented in Visual C++ 6.0 (García-Sevilla et al., 2000). The above program was run on a PC-compatible computer based on a Pentium III/450 MHz processor with 128 Mbytes of RAM. Data thus obtained and the corresponding analytical solutions were plotted using the SigmaPlot Scientific Graphing System for Windows version 4.00 which was also used to obtain the corresponding values of the statistical parameters $g(j)(j=3,6,9)$ given by Eqn. $(84)$.

\section{A MODEL OF AN OPEN MULTICYCLIC CAS- CADE SYSTEM}

We studied a $\mathrm{N}$-cycle cascade system that coincides, except in part of the notation, with the one proposed for the steady state by Chock and Stadtman $(1977 ; 1980)$. This system is shown in the following scheme:

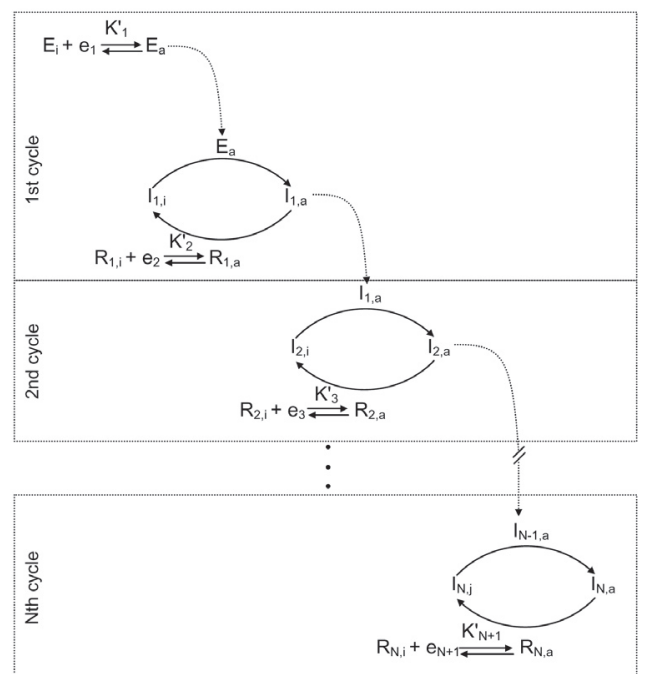

\section{Scheme 1.}

where $\mathrm{e}_{1}, \mathrm{e}_{2}, \ldots, \mathrm{e}_{\mathrm{N}+1}$ are the allosteric effectors, $\mathrm{E}_{\mathrm{i}}, \mathrm{R}_{1, \mathrm{i}}, \ldots, \mathrm{R}_{\mathrm{N}, \mathrm{i}}$ the inactive converting enzymes, $\mathrm{E}_{\mathrm{a}^{\prime}}, \mathrm{R}_{1, \mathrm{a}^{\prime}}, \ldots, \mathrm{R}_{\mathrm{N}, \mathrm{a}}$ the active converting enzymes, $\mathrm{I}_{1, \mathrm{i}}, \mathrm{I}_{2, \mathrm{i}}, \ldots, \mathrm{I}_{\mathrm{N}, \mathrm{i}}$ the inactive interconvertible enzymes and $\mathrm{I}_{1, \mathrm{a}^{\prime}} \mathrm{I}_{2, \mathrm{a}}, \ldots, \mathrm{I}_{\mathrm{N}, \mathrm{a}}$ the active interconvertible enzymes.

The set of reactions of this system is given in the more detailed Scheme 2.

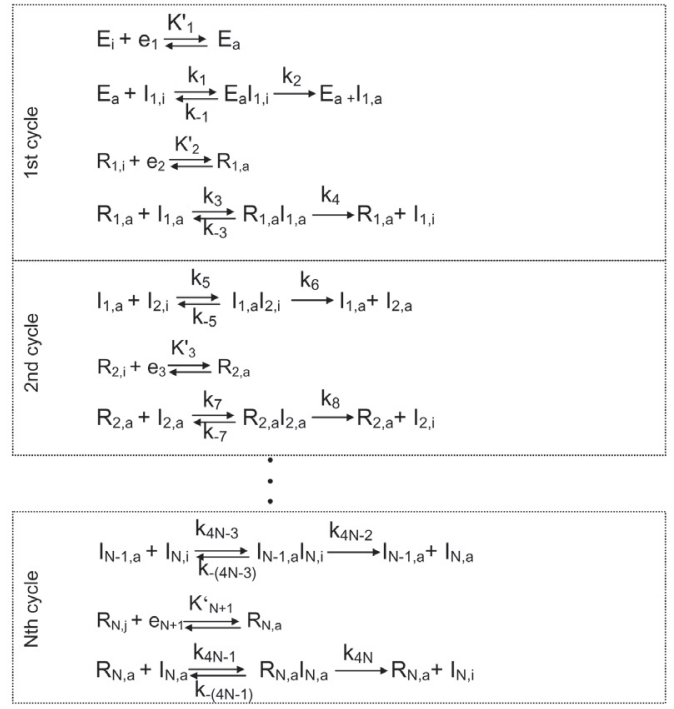

Scheme 2.

\section{Assumptions}

We assume that:

1) The reactions of the converter enzymes with their allosteric effectors, i.e. the steps

$\mathrm{E}_{\mathrm{i}}+\mathrm{e}_{1} \rightleftarrows \mathrm{E}_{\mathrm{a}}$ and $\mathrm{R}_{\mathrm{j}, \mathrm{i}}+\mathrm{e}_{\mathrm{j}+1} \rightleftarrows \mathrm{R}_{\mathrm{i}, \mathrm{a}^{\prime}}$ are in a state of rapid equilibrium. This assumption is already implied in Schemes 1 and 2.

2) $\left[\mathrm{E}_{\mathrm{a}} \mathrm{I}_{1, \mathrm{i}}\right] \ll\left[\mathrm{E}_{\mathrm{i}}\right],\left[\mathrm{E}_{\mathrm{a}}\right]$

$$
\left[\mathrm{R}_{\mathrm{j}, \mathrm{a}} \mathrm{I}_{\mathrm{j}, \mathrm{a}}\right] \ll\left[\mathrm{R}_{\mathrm{j}, \mathrm{i}}\right],\left[\mathrm{R}_{\mathrm{j}, \mathrm{a}}\right](\mathrm{j}=1,2, \ldots, \mathrm{N})
$$

From the relations (1) and (2) as well as from Scheme 2, we deduce:

$$
\begin{aligned}
& {[\mathrm{E}] \approx\left[\mathrm{E}_{\mathrm{i}}\right]+\left[\mathrm{E}_{\mathrm{a}}\right]} \\
& {\left[\mathrm{R}_{\mathrm{j}}\right] \approx\left[\mathrm{R}_{\mathrm{j}, \mathrm{i}}\right]+\left[\mathrm{R}_{\mathrm{j}, \mathrm{a}}\right] \quad(\mathrm{j}=1,2, \ldots, \mathrm{N})}
\end{aligned}
$$

3) $\left[e_{j}\right](j=1,2, \ldots, N+1)$ are maintained at constant levels. This implies that the allosteric effectors $e_{j}$ either are present in excess or continuously produced and fed into the system at a rate commensurate with their conversion.

Assumptions 1-3 predict that the $\mathrm{E}_{\mathrm{a}}$ and $\mathrm{R}_{\mathrm{i}, \mathrm{a}}$ $(j=1,2, \ldots, N)$ concentrations remain constant from the onset of the reaction and that their values are given by the equations:

$$
\begin{aligned}
& {\left[E_{a}\right]=\frac{\left[E \llbracket e_{1}\right]}{K_{1}^{\prime}+\left[e_{1}\right]}} \\
& {\left[R_{j, a}\right]=\frac{\left[R_{j} \amalg e_{j+1}\right]}{K_{j+1}^{\prime}+\left[e_{j+1}\right]} \quad(\mathrm{j}=1,2, \ldots, \mathrm{N})}
\end{aligned}
$$

where $K_{1}^{\prime}$ and $K^{\prime}{ }_{j+1}$ are the dissociation constants of $E_{a}$ and $R_{j, a}(j=1,2, \ldots, N)$, respectively. These assumptions, among others, were made by other authors to obtain steady state equations of these cascades (Chock \& Stadtman, 1977; 1980). Hence, the kinetics of Scheme 2 are equivalent to that of the following Scheme 3:

${ }^{1}$ The appendices are published only as pdf files on the www (www.actabp.pl) line version not in the printed form. 


$$
\begin{aligned}
& \text { थ } \quad E_{a}+l_{1, i} \underset{k_{-1}}{\stackrel{k_{1}}{\rightleftarrows}} E_{a} l_{1, i} \stackrel{k_{2}}{\longrightarrow} E_{a}+l_{1, a} \\
& \stackrel{\text { ज. }}{\stackrel{0}{0}} R_{1, a}+l_{1, a} \underset{k_{-3}}{\stackrel{k_{3}}{\longrightarrow}} R_{1, a} l_{1, a} \stackrel{k_{4}}{\longrightarrow} R_{1, a}+l_{1, i}
\end{aligned}
$$

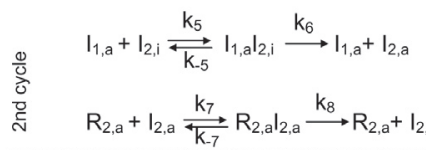

$$
\begin{aligned}
& \begin{array}{c}
k_{-7} \\
\vdots
\end{array} \\
& \begin{array}{l}
\frac{0}{\bar{y}} \\
\text { 产 }
\end{array}
\end{aligned}
$$

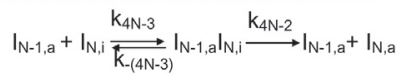

$$
\begin{aligned}
& \text { 言 } \quad R_{N, a}+I_{N, a} \underset{k_{-(4 N-1)}}{\stackrel{k_{4 N-1}}{\longrightarrow}} R_{N, a} a_{N, a} \stackrel{k_{4 N}}{\longrightarrow} R_{N, a}+I_{N, i}
\end{aligned}
$$

Scheme 3 .

where $\left[E_{a}\right]$ and $\left[R_{j, a}\right](j=1,2, \ldots, N)$ are given by Eqns. (5) and (6).

4) The concentrations of the unmodified enzymes $\mathrm{I}_{2, \mathrm{i}} \mathrm{I}_{3,1}, \ldots, \mathrm{I}_{\mathrm{N}, \mathrm{i}}$ remain approximately constant during the whole course of the reaction time assayed. This implies that, at any time, the species $\mathrm{I}_{\mathrm{j}, \mathrm{i}}$ $(j=2,3, \ldots, N)$ either are present in excess with regard to $I_{j-1, a}(j=2,3, \ldots, N)$ or continuously produced and fed into the system at a rate commensurate with their conversion. This assumption is reasonable and necessary to linearise the differential equations of the reactions in Scheme 3.

\section{Notation and definitions}

The kinetic analysis presented here requires the introduction of appropriate notations and definitions to make it easier and comprehensible. In this section we summarise those notations and definitions which will be used in the following sections.

\section{Species and mechanism}

Systematic treatment of the complex Scheme 3 requires a simple set of notation and definitions. We suggest the following one:
$\mathrm{E}_{\mathrm{a}}=\mathrm{Y}_{\mathrm{i}}$
$\mathrm{I}_{1, \mathrm{i}}=\mathrm{X}_{1}$
$\mathrm{I}_{\mathrm{n}, \mathrm{i}}=\mathrm{Y}_{\mathrm{n}}$
$\mathrm{R}_{\mathrm{n}, \mathrm{a}}=Z_{\mathrm{n}}$
$(\mathrm{n}=2,3, \ldots, \mathrm{N})$
$\mathrm{I}_{\mathrm{n}, \mathrm{a}}=\mathrm{X}_{3 \mathrm{n}}$
$(\mathrm{n}=1,2, \ldots, \mathrm{N})$
$\mathrm{E}_{\mathrm{a}} \mathrm{I}_{\mathrm{l}, \mathrm{i}}=\mathrm{X}_{2}$
$\mathrm{I}_{\mathrm{n}-1, \mathrm{a}, \mathrm{I}, \mathrm{i}}=\mathrm{X}_{3 \mathrm{n}-\mathrm{1}}$
$(\mathrm{n}=1,2, \ldots, \mathrm{N})$
$\mathrm{R}_{\mathrm{n}, \mathrm{a}} \mathrm{I}_{\mathrm{n}, \mathrm{a}}=\mathrm{X}_{3 \mathrm{n}+1}$
$(\mathrm{n}=2,3, \ldots, \mathrm{N})$
$\left[Y_{j}\right]$ : concentration of $Y_{j}$ at time $t$
$(\mathrm{n}=1,3, \ldots, \mathrm{N})$
$(\mathrm{j}=1,2, \ldots, \mathrm{N})$
$\left[\mathrm{Y}_{\mathrm{j}}\right]_{0}$ : concentration of $\mathrm{Y}_{\mathrm{j}}$ at $t=0$
$(\mathrm{j}=1,2, \ldots, \mathrm{N})$
$\left[\mathrm{X}_{\mathrm{i}}\right]$ : concentration of $\mathrm{X}_{\mathrm{i}}$ at time $t$
$(\mathrm{i}=1,2, \ldots, 3 \mathrm{~N}+1)$
$\left[\mathrm{X}_{\mathrm{i}}\right]_{0}$ : concentration of $\mathrm{Y}_{\mathrm{j}}$ at $t=0$
$(\mathrm{i}=1,2, \ldots, 3 \mathrm{~N}+1)$
$\left[\mathrm{Z}_{\mathrm{j}}\right]$ : concentration of $\mathrm{Z}_{\mathrm{j}}$ at time
$(\mathrm{j}=1,2, \ldots, \mathrm{N})$
$\left[\mathrm{Z}_{\mathrm{j}}\right]_{0}$ : concentration of $\mathrm{Y}_{\mathrm{j}}$ at $t=0$
$(\mathrm{j}=1,2, \ldots, \mathrm{N})$
$\left[\dot{X}_{i}\right]$ : time derivative of $\left[\mathrm{X}_{\mathrm{i}}\right]$, i.e. $\mathrm{d}\left[\mathrm{X}_{\mathrm{i}}\right] / \mathrm{dt} \quad(\mathrm{i}=1,2, \ldots, 3 \mathrm{~N}+1)$
$\left[\dot{Y}_{j}\right]$ : time derivative of $\left[\mathrm{Y}_{\mathrm{j}}\right]$, i.e. $\mathrm{d}\left[\mathrm{Y}_{\mathrm{j}}\right] / \mathrm{dt} \quad(\mathrm{j}=1,2, \ldots, \mathrm{N})$

Using the above notation, Scheme 3 takes the form:

$$
\begin{aligned}
& \left.\begin{array}{l}
Y_{1}+X_{1} \underset{k_{-1}}{\stackrel{k_{1}}{\rightleftarrows}} X_{2} \stackrel{k_{2}}{\longrightarrow} Y_{1}+X_{3} \\
Z_{1}+X_{3} \underset{k_{-3}}{\stackrel{k_{3}}{\longrightarrow}} X_{4} \stackrel{k_{4}}{\longrightarrow} Z_{1}+X_{1}
\end{array}\right\} \text { 1st cycle } \\
& \left.\begin{array}{l}
Y_{n}+X_{3(n-1)} \underset{k_{-(4 n-3)}}{\stackrel{k_{4 n-3}}{\rightleftarrows}} X_{3 n-1} \stackrel{k_{4 n-2}}{\longrightarrow} X_{3(n-1)}+X_{3 n} \\
Z_{n}+X_{3 n} \underset{k_{-(4 n-1)}}{\stackrel{k_{4 n-1}}{\longrightarrow}} X_{3 n+1} \stackrel{k_{4 n}}{\longrightarrow} Z_{n}+Y_{n}
\end{array}\right\} \begin{array}{l}
\text { nth-cycle } \\
\text { (n=2 up to } N)
\end{array}
\end{aligned}
$$

Scheme 4.

Note that with the assumptions 1-4 and the notation for the species and mechanism above the interconversions of the species $X_{i} \quad(i=1,2, \ldots, 3 \mathrm{~N}+1)$ are either of first order or of pseudo-first order, being $k_{-(4 n-3)}(\mathrm{n}=1,2, \ldots, N)$ and $k_{4 n-2}(\mathrm{n}=1,2, \ldots, N)$ the first order rate constants and $k_{4 \mathrm{n}-3}\left[\mathrm{Y}_{\mathrm{n}}\right]_{0}(\mathrm{n}=1,2, \ldots, \mathrm{N})$ and $k_{4 \mathrm{n}-1}\left[\mathrm{Z}_{\mathrm{n}}\right]_{0}(\mathrm{n}=1,2, \ldots, \mathrm{N})$ the pseudo-first rate constants. It is easy to represent these first order interconversions through a directed graph as that shown in Scheme 5. In this scheme we have indicated the steps corresponding to the connection of two cycles by means of dashed lines. The circles delimit the classes $\mathrm{C}_{1}, \mathrm{C}_{2}, \ldots, \mathrm{C}_{\mathrm{N}}$ in the graph. Each class contains those species $X_{i}$ so that any of them has influence on each of the others belonging to the same class (Gálvez \& Varón, 1981). One must not confound a class with a cycle. Note that to class $C_{1}$ belong the species involved in the first cycle (i.e. $X_{1}, X_{2}, X_{3}$ and $X_{4}$ ) and also the species $X_{5}$ (involved in the second cycle). Likewise, to the $n$-th class $(n=2,3, \ldots, N-1)$ belong the species $X_{3 n}$ and $X_{3 n+1}$, which are involved in the $n$-th cycle (the species $X_{3 n-1}$, also involved in the $n$-th cycle, belongs to class $C_{n-1}$ ) and the species $X_{3 n+2}$ involved in the next cycle. Finally, to the last class $\left(C_{N}\right)$ belong the two species $X_{3 N}$ and $X_{3 N+1}$. The concept of class in a directed graph is also called a strong component of the graph (Jacquez, 1996).

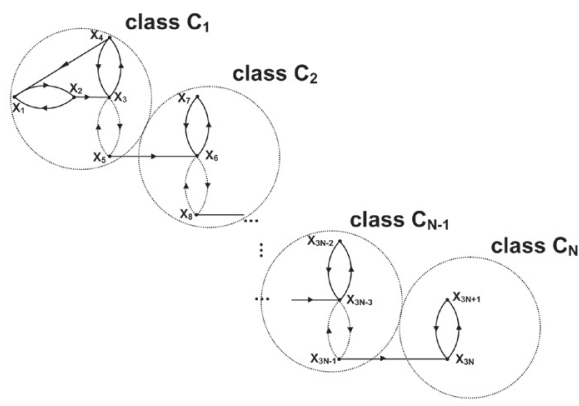

Scheme 5 .

i $(i=1,2, \ldots, 3 N+1)$ : Index which can take any of the values $1,2, \ldots, 3 \mathrm{~N}+1$ corresponding to the subscripts in the notation $X_{i}$ of any of the $3 N+1$ enzyme species so denoted.

$\mathrm{u}(\mathrm{i})$ : The subindex corresponding to the class to which the species $X_{i}(i=1,2, \ldots, 3 N+1)$ belongs. Therefore $\mathrm{u}(\mathrm{i})$ can take the values $1,2, \ldots, \mathrm{N}$. For example, 
$X_{6}$ belongs to class $C_{2}$ (see Scheme 5) so that $u(6)=2$. Note that $\mathrm{u}(1)=\mathrm{u}(2)=\ldots=\mathrm{u}(5)=1$ and if $\mathrm{i}>2$, then $\mathrm{u}(\mathrm{i})$ coincides with the integer part of the quotient $i / 3$. $\mathrm{f}$ : takes the value of 0 if $\mathrm{u}(\mathrm{i})<\mathrm{N}$ and 1 if $\mathrm{u}(\mathrm{i})=\mathrm{N}$ $\mathrm{v}(\mathrm{i})$ : Integer, $\mathrm{i}$-dependent number defined as the minimum value of the index $i$ of the species $X_{i}$ belonging to the class $\mathrm{C}_{\mathrm{u}(\mathrm{i})}$. For example, for $\mathrm{i}=8$ $(\mathrm{u}(\mathrm{i})=2), \mathrm{v}(\mathrm{i})=6$.

$$
v(i)=\left\{\begin{array}{lll}
1 & \text { if } & u(i)=1 \\
3 u(i) & \text { if } & u(i)>1
\end{array}\right.
$$

w(i): Integer, i-dependent number defined as the total number of species $X_{i}$ belonging to the classes $C_{1}$, $\mathrm{C}_{2}, \ldots, \mathrm{C}_{\mathrm{u}(\mathrm{i})}$. For example, if $\mathrm{i}=6$ (and, therefore $\mathrm{u}(\mathrm{i})=2$ ) then $w(6)$ is the sum of the number of species $X$ belonging to $C_{1}$ (i.e. 5) and to $C_{2}$ (i.e. 3), i.e. $w(6)=$ $5+3=8$. Note that:

$$
w(i)=\left\{\begin{array}{lll}
5 & \text { if } & u(i)=1 \\
3 u(i)+2 & \text { if } & 1<u(i)<N \\
3 N+1 & \text { if } & u(i)=N
\end{array}\right.
$$

From Eqns. (8) and (9) and the meaning of the number $\mathrm{f}$ defined above we can state that the sum $\mathrm{v}(\mathrm{i})+\mathrm{w}(\mathrm{i})+\mathrm{f}$ is always even.

In Table 1 we list all possible values of numbers $\mathrm{i}, \mathrm{u}(\mathrm{i}), \mathrm{f}, \mathrm{v}(\mathrm{i})$ and $\mathrm{w}(\mathrm{i})$ for a tetracyclic cascade system (it contains $3 \mathrm{~N}+1=13$ enzyme species $X_{i}$ $(i=1,2, \ldots, 13))$.

\section{Matrices}

$\mathrm{D}_{\mathrm{u}(\mathrm{i})}$ ( $\left.\lambda\right) \quad(\mathrm{u}(\mathrm{i})=1,2, \ldots, \mathrm{N})$ : $\mathrm{w}(\mathrm{i})$-order square matrix which can be expressed in submatrices as:

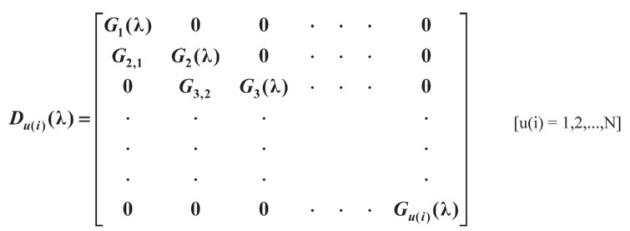

where:

$$
G_{I}(\lambda)=\left[\begin{array}{ccccc}
-k_{1}\left[Y_{1}\right]_{0}-\lambda & k_{-1} & 0 & k_{4} & 0 \\
k_{1}\left[Y_{1}\right]_{0} & -\left(k_{-1}+k_{2}\right)-\lambda & 0 & 0 & 0 \\
0 & k_{2} & -\left(k_{5}\left[Z_{1}\right]_{0}+k_{5}\left[Y_{2}\right]_{0}\right)-\lambda & k_{-3} & k_{-5}+k_{6} \\
0 & 0 & k_{5}\left[Z_{1}\right]_{0} & -\left(k_{-3}+k_{4}\right)-\lambda & 0 \\
0 & 0 & k_{5}\left[Y_{2}\right]_{0} & 0 & -\left(k_{-5}+k_{6}\right)-\lambda
\end{array}\right]
$$

$G_{j}(\lambda)=\left[\begin{array}{ccc}-\left(k_{4 j-1}\left[Z_{j}\right]_{0}+k_{4 j+1}\left[Y_{j+1}\right]_{0}\right)-\lambda & k_{-(4 j-1)} & k_{-(j+1)}+k_{4 j+2} \\ k_{4 j-1}\left[Z_{j}\right]_{0} & -\left(k_{-4 j-1)}+k_{4 j}\right)-\lambda & 0 \\ k_{4 j+1}\left[Y_{j+1}\right]_{0} & 0 & -\left(k_{-(j+1)}+k_{4 j+2}\right)-\lambda\end{array}\right](\mathrm{N}>2 ; 1<j<\mathrm{N})$

$\boldsymbol{G}_{N}(\lambda)=\left[\begin{array}{cc}-k_{4 N-1}\left[Z_{N}\right]_{0}-\lambda & k_{-(4 N-1)} \\ k_{4 N-1}\left[Z_{N}\right]_{0} & -\left(k_{-(4 N-1)}+k_{4 N}\right)-\lambda\end{array}\right]$

The other non-null submatrices of the main diagonal in the matrix (10) are:

$$
\boldsymbol{G}_{2, I}=\left[\begin{array}{ccccc}
0 & 0 & 0 & 0 & k_{6} \\
0 & 0 & 0 & 0 & 0 \\
0 & 0 & 0 & 0 & 0
\end{array}\right]
$$

If $N=2$, then $G_{2,1}$ is given by the matrix in Eqn. (14) in which the last row is missing.

$$
\begin{aligned}
\boldsymbol{G}_{j, j-1} & =\left[\begin{array}{ccc}
0 & 0 & k_{4 j-2} \\
0 & 0 & 0 \\
0 & 0 & 0
\end{array}\right] & (\mathrm{N}>2 ; 2<\mathrm{j}<\mathrm{N}) \\
\boldsymbol{G}_{N, N-1} & =\left[\begin{array}{ccc}
0 & 0 & k_{4 N-2} \\
0 & 0 & 0
\end{array}\right] & (\mathrm{N}>2)
\end{aligned}
$$

The null matrix of the a-th row $[a=1,2, \ldots, u(i)]$ and the $b$-th column $[b=1,2, \ldots, u(i)]$ has the same number of rows as that of matrix $G_{a}(\lambda)$ and the same number of columns as that of matrix $G_{b}(\lambda)$.

$D_{u(i)}(0)(u(i)=1,2, \ldots, N)$ : Matrix with all its entries being constants obtained from matrix $D_{\mathbf{u}(\mathbf{i})}(\lambda)$ $(\mathrm{u}(\mathrm{i})=1,2, \ldots, \mathrm{N})$ by setting $\lambda=0$ in it.

$\mathrm{D}_{\mathrm{u}(\mathrm{i})}(\lambda)_{\mathrm{i}}(\mathrm{u}(\mathrm{i})=1,2, \ldots, \mathrm{N})$ : Matrix obtained by removal of the first row and the i-th column in matrix $\mathrm{D}_{\mathrm{u}(\mathrm{i})}(\lambda)$. It has the general form:

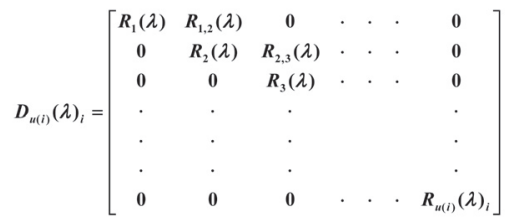

where:

$\boldsymbol{R}_{I}(\lambda)=\left[\begin{array}{ccccc}k_{1}\left[Y_{1}\right]_{0} & -\left(k_{-1}+k_{2}\right)-\lambda & 0 & 0 & 0 \\ 0 & k_{2} & -\left(k_{5}\left[Z_{1}\right]_{0}+k_{5}\left[Y_{2}\right]_{0}\right)-\lambda & k_{-3} & k_{-5}+k_{6} \\ 0 & 0 & k_{5}\left[Z_{7}\right]_{0} & -\left(k_{-3}+k_{4}\right)-\lambda & 0 \\ 0 & 0 & k_{5}\left[Y_{2}\right]_{0} & 0 & -\left(k_{-5}+k_{6}\right)-\lambda \\ 0 & 0 & 0 & 0 & k_{6}\end{array}\right]$

$\boldsymbol{R}_{j}(\lambda)=\left[\begin{array}{ccc}k_{4 j-1}\left[Z_{j}\right]_{0} & -\left(k_{-(4 j-1)}+k_{4 j}\right)-\lambda & 0 \\ k_{4 j+1}\left[Y_{j+1}\right]_{0} & 0 & -\left(k_{-(4 j+1)}+k_{4 j+2}\right)-\lambda \\ 0 & 0 & k_{4 j+2}\end{array}\right]$

$[\mathrm{j}=2,3, \ldots, \mathrm{u}(\mathrm{i})-1]$

Three cases must be distinguished to express $\mathrm{R}_{\mathrm{u}(\mathrm{i})}(\lambda)_{\mathrm{i}}$ : a) $\mathrm{i} \leq 5$ [i.e. $\mathrm{u}(\mathrm{i})=1$ ]; b) $5<\mathrm{i} \leq 3 \mathrm{~N}-1$ [i.e. $1<\mathrm{u}(\mathrm{i})<\mathrm{N}$ ] and c) $\mathrm{i} \geq 3 \mathrm{~N}$ [i.e. $\mathrm{u}(\mathrm{i})=\mathrm{N}$ ].

a) $\mathrm{u}(\mathrm{i})=1$ (i.e. $\mathrm{i} \leq 5)$ :

In this case $R_{1}(\lambda)_{i}$ is the matrix obtained by removal of the first row and the i-th column in matrix $G_{1}(\lambda)$. Equation (10) is then simplified into: $D_{1}(\lambda)_{i}=R_{1}(\lambda)_{\mathrm{i}}$

b) $1<\mathrm{u}(\mathrm{i})<\mathrm{N}$ (i.e. $5<\mathrm{i}<3 \mathrm{~N})$ :

In this case:

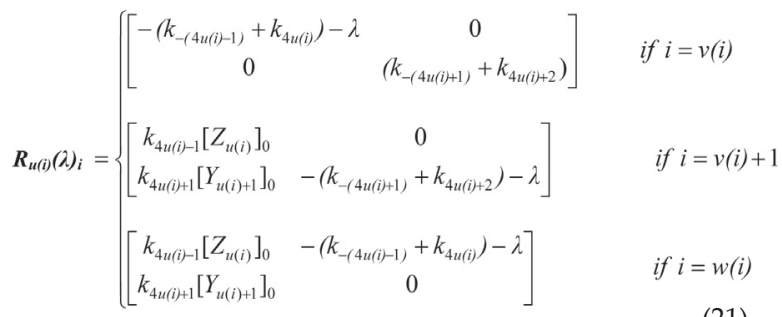


c) $u(i)=N$ (i.e. $i=3 N$ or $3 N+1$ ):

In this case:

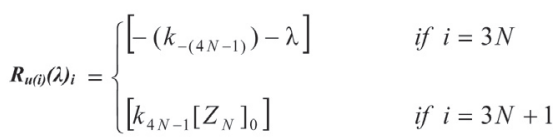

Hence, the non-null submatrices of the main diagonal in matrix (17) are:

$$
\boldsymbol{R}_{l, 2}(\lambda)=\left[\begin{array}{ccc}
0 & 0 & 0 \\
0 & 0 & 0 \\
0 & 0 & 0 \\
0 & 0 & 0 \\
-\left(k_{7}\left[Z_{2}\right]_{0}+k_{9}\left[Y_{3}\right]_{0}\right)-\lambda & k_{-7} & k_{-9}+k_{10}
\end{array}\right]
$$

$(\mathrm{N}>2)$
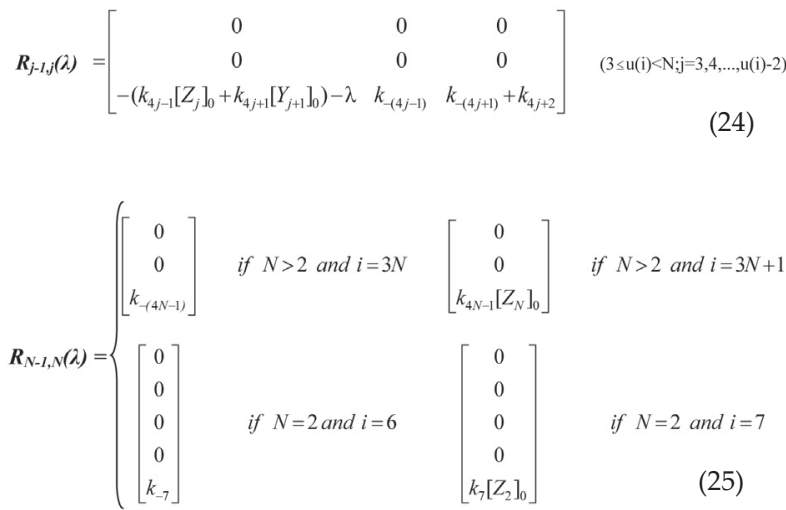

Any null submatrix in row a $(\mathrm{a}=1,2, \ldots, \mathrm{u}(\mathrm{i}))$ and in column $b(b=1,2, \ldots, u(i))$ of matrix $D_{u(i)}(\lambda)_{i}$ has the same number of rows as that of matrix $R_{a}$ and the same number of columns as that of matrix $R_{b}$.

$\dot{V}_{i}:$

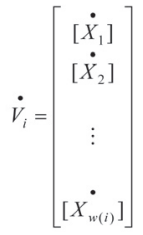

$\mathbf{v}_{\mathrm{i}}$

$V_{i}=\left[\begin{array}{c}{\left[X_{1}\right]} \\ {\left[X_{2}\right]} \\ \vdots \\ {\left[X_{w(i)}\right]}\end{array}\right]$

$\mathrm{L}\left\{\left[\mathrm{X}_{\mathrm{i}}\right]\right\}$ : Laplace transform of $\left[\mathrm{X}_{\mathrm{i}}\right]$

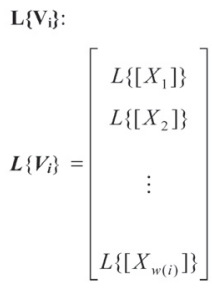

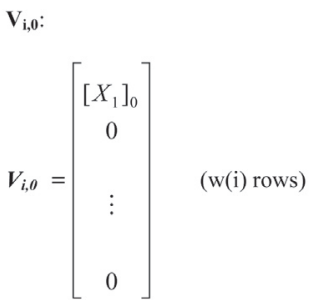

Table 1. Values of the integer numbers $u(i), f, v(i)$ and $w(i)$ for the different i-values in a tetracyclic cascade system

\begin{tabular}{ccccc}
\hline $\mathrm{i}$ & $\mathrm{u}(\mathrm{i})$ & $\mathrm{f}$ & $\mathrm{v}(\mathrm{i})$ & $\mathrm{w}(\mathrm{i})$ \\
\hline 1 & 1 & 0 & 1 & 5 \\
2 & 1 & 0 & 1 & 5 \\
3 & 1 & 0 & 1 & 5 \\
4 & 1 & 0 & 1 & 5 \\
5 & 1 & 0 & 1 & 5 \\
6 & 2 & 0 & 6 & 8 \\
7 & 2 & 0 & 6 & 8 \\
8 & 2 & 0 & 6 & 8 \\
9 & 3 & 0 & 9 & 11 \\
10 & 3 & 0 & 9 & 11 \\
11 & 3 & 0 & 9 & 11 \\
12 & 4 & 1 & 13 & 13 \\
13 & 4 & 1 & 13 & 13 \\
\hline
\end{tabular}

Determinants and polynomials

$\mathrm{d}_{\mathrm{u}(\mathrm{i})}(\lambda)(\mathrm{i}=1,2, \ldots, 3 \mathrm{~N}+1)$ : Determinant of matrix $\mathrm{D}_{\mathrm{u}(\mathrm{i})}(\lambda)$ in Eqn. (10). Its expansion yields a polynomial in $\lambda$ of the degree $\mathrm{w}(\mathrm{i})$.

$g_{j}(\lambda) \quad(j=1,2, \ldots, u(i))$ : Determinants of matrix $G_{j}(\lambda)$ $(j=1,2, \ldots, u(i))$ in Eqns. (11)-(13). Their expressions are:

$\mathrm{g}_{1}(\lambda)=-\lambda\left(\lambda^{4}+a_{1,3} \lambda^{3}+a_{1,2} \lambda^{2}+a_{1,1} \lambda+a_{1,0}\right)$

$\mathrm{g}_{\mathrm{j}}(\lambda)=-\left(\lambda^{3}+a_{\mathrm{j}, 2} \lambda^{2}+a_{\mathrm{j}, 1} \lambda+a_{\mathrm{j}, 0}\right) \quad(\mathrm{j}=2,3, \ldots, \mathrm{N}-1)$

$\mathrm{g}_{\mathrm{N}}(\lambda)=\lambda^{2}+a_{\mathrm{N}, 1} \lambda+a_{\mathrm{N}, 0}$

The expressions for the coefficients $a_{1,3^{\prime}}$ $a_{\mathrm{j}, 2}(\mathrm{j}=1,2, \ldots, \mathrm{N}-1), a_{\mathrm{j}, 1}(\mathrm{j}=1,2, \ldots, \mathrm{N})$ and $a_{\mathrm{j}, 0}(\mathrm{j}=1,2, \ldots, \mathrm{N})$ in Eqns. (30)-(32) are summarized in Eqns. (A1)-(A9) in Appendix A.

$\mathrm{d}_{\mathrm{u}(\mathrm{i})}(\lambda)_{\mathrm{i}} \quad(\mathrm{u}(\mathrm{i})=1,2, \ldots, \mathrm{N})$ : Determinant matrix $\mathrm{D}_{\mathrm{u}(\mathrm{i})}(\lambda)_{\mathrm{i}}$ given in Eqn. (17).

$r_{j}(\lambda)(j=1,2, \ldots, u(i)-1)$ : Determinants of matrices $\mathbf{R}_{\mathrm{j}}(\lambda)(\mathrm{j}=1,2, \ldots, \mathrm{u}(\mathrm{i})-1)$ given in Eqns. (18) and (19). According to Eqns. (18) and (19) one obtains for $r_{j}(\lambda)$ :

$\mathrm{r}_{\mathrm{j}}(\lambda)=b_{\mathrm{j}, 1} \lambda+b_{\mathrm{j}, 0} \quad(\mathrm{j}=1,2, \ldots, \mathrm{u}(\mathrm{i})-1)$

The coefficients $b_{\mathrm{j}, 1}$ and $b_{\mathrm{j}, 0}$ are given in Eqns. (A10)-(A13) of Appendix A.

$\mathrm{r}_{\mathrm{u}(\mathrm{i})}(\lambda)_{\mathrm{i}}(\mathrm{u}(\mathrm{i})=1,2, \ldots, \mathrm{N})$ : Determinants of matrices $\mathbf{R}_{\mathbf{u}(\mathrm{i})}(\lambda)_{i}(\mathrm{u}(\mathrm{i})=1,2, \ldots, N)$ given in Eqns. (20)-(22). For the expression of $r_{u(i)}(\lambda)_{i}$ obtained from the expansion of the corresponding determinant we distinguish between the same case (a) $-(\mathrm{c})$, as those of matrices $\mathbf{R}_{\mathbf{u}(\mathbf{i})}(\lambda)_{\mathbf{i}}$ :

(a) $\mathrm{u}(\mathrm{i})=1$ (i.e. $\mathrm{i} \leq 5)$ : 
$\mathrm{r}_{1}(\lambda)_{\mathrm{i}}=(-1)^{1+\mathrm{i}}\left\{b_{1,4}(\mathrm{i}) \lambda^{4}+b_{1,3}(\mathrm{i}) \lambda^{3}+b_{1,2}(\mathrm{i}) \lambda^{2}+b_{1,1}(\mathrm{i}) \lambda+b_{1,0}(\mathrm{i})\right\}$

(b) $1<\mathrm{u}(\mathrm{i})<\mathrm{N}$ (i.e. $5<\mathrm{i}<3 \mathrm{~N})$ :

$\mathrm{r}_{\mathrm{u}(\mathrm{i})}(\lambda)_{\mathrm{i}}=(-1)^{\mathrm{v}(\mathrm{i})+\mathrm{i}}\left\{b_{\mathrm{u}(\mathrm{i}), 1}(\mathrm{i}) \lambda+b_{\mathrm{u}(\mathrm{i}), 0}(\mathrm{i})\right\} \quad(\mathrm{u}(\mathrm{i})=2,3, \ldots, \mathrm{N}-1)$

(c) $\mathrm{u}(\mathrm{i})=\mathrm{N}$ (i.e. $\mathrm{i}=3 \mathrm{~N}$ or $3 \mathrm{~N}+1)$ :

$\mathrm{r}_{\mathrm{N}}(\lambda)_{\mathrm{i}}=(-1)^{3 \mathrm{~N}+\mathrm{i}+1}\left(\mathrm{~b}_{\mathrm{i}, 1}(\mathrm{i}) \lambda+b_{\mathrm{i}, 0}(\mathrm{i})\right) \quad(\mathrm{i}=3 \mathrm{~N}, 3 \mathrm{~N}+1)$

The coefficients $\quad b_{1,4}(\mathrm{i}), \quad b_{1,3}(\mathrm{i}), \quad b_{1,2}(\mathrm{i})$, $b_{1,1}(\mathrm{i}), \quad b_{1,0}(\mathrm{i}), \quad b_{\mathrm{u}(\mathrm{i}), 1}(\mathrm{i}) \quad(\mathrm{u}(\mathrm{i})=2,3, \ldots, \mathrm{N}) \quad$ and $\quad b_{\mathrm{u}(\mathrm{i}), 0}(\mathrm{i})$ $(\mathrm{u}(\mathrm{i})=2,3, \ldots, \mathrm{N})$ depend on the i-value $(\mathrm{i}=1,2, \ldots$, $3 u(i)+1)$ and they are given in Appendix A (Eqns. (A14)-(A34)).

\section{Theoretical}

Eigenvalues of matrices $D_{u(i)}(0)$

They are the roots of the polynomial $\mathrm{d}_{\mathrm{u}(\mathrm{i})}(\lambda)$. Since the degree of $\mathrm{d}_{\mathrm{u}(\mathrm{i})}(\lambda)$ is $\mathrm{w}(\mathrm{i})$, the roots are $\lambda_{1}$, $\lambda_{2}, \ldots, \lambda_{\mathrm{w}(\mathrm{i})}$.

From Eqn. (10) and the theory of determinants it follows that:

$d_{u(i)}(\lambda)=\prod_{j=1}^{u(i)} g_{i}(\lambda) \quad(\mathrm{u}(\mathrm{i})=1,2, \ldots, \mathrm{N})$

Therefore the roots $\lambda_{\mathrm{h}}(\mathrm{h}=1,2, \ldots, \mathrm{w}(\mathrm{i}))$ of $\mathrm{d}_{\mathrm{u}(\mathrm{i})}(\lambda)$ coincide with the roots of the polynomials $g_{1}(\lambda)$, $\mathrm{g}_{2}(\lambda), \ldots, \mathrm{g}_{\mathrm{u}(\mathrm{i})}(\lambda)$.

The polynomial $g_{1}(\lambda)$ has the roots $\lambda_{1}, \lambda_{2}, \ldots$, $\lambda_{5}$. The form of this polynomial (see Eqn. (30) and that $a_{1,0} \neq 0$ ) requires that one, and only one, of these roots, namely $\lambda_{1}$, is null.

We name the roots of any of the polynomials $\mathrm{g}_{\mathrm{j}}(\lambda)(\mathrm{j}=2,3, \ldots, \mathrm{u}(\mathrm{i})-1)$ as $\lambda_{\mathrm{v}[\mathrm{j}]^{\prime}} \lambda_{\mathrm{v}[\mathrm{j}]+1}$ and $\lambda_{\mathrm{w}(\mathrm{j})}$ and those of the polynomials $g_{\mathrm{N}}(\lambda)$ as $\lambda_{3 \mathrm{~N}}$ and $\lambda_{3 \mathrm{~N}+1}$. Since in Eqns. (31) and (32) $a_{\mathrm{j}, 0} \neq 0$, none of these roots is null.

The polynomial theory and the notation used for the roots yield the equations:

$\mathrm{g}_{1}(\lambda)=-\lambda\left(\lambda-\lambda_{2}\right)\left(\lambda-\lambda_{3}\right)\left(\lambda-\lambda_{4}\right)\left(\lambda-\lambda_{5}\right)$

$\mathrm{g}_{\mathrm{j}}(\lambda)=-\left(\lambda-\lambda_{\mathrm{v}[\mathrm{j}]}\right)\left(\lambda-\lambda_{\mathrm{v}[\mathrm{j}]+1}\right)\left(\lambda-\lambda_{\mathrm{w}[\mathrm{j}]}\right)(\mathrm{j}=2,3, \ldots, \mathrm{N}-1)$

and

$\mathrm{g}_{\mathrm{N}}(\lambda)=\left(\lambda-\lambda_{3 \mathrm{~N}}\right)\left(\lambda-\lambda_{3 \mathrm{~N}+1}\right)$

Insertion of Eqns. (38)-(40) into Eqn. yields the expression:

$d_{u(i)}(\lambda)=(-1)^{w(i)} \lambda \prod_{h=2}^{w(i)}\left(\lambda-\lambda_{h}\right)$

The matrices $\mathbf{G}_{\mathbf{1}}(\mathbf{0}), \mathbf{G}_{\mathbf{2}}(\mathbf{0}), \ldots, \mathbf{G}_{\mathbf{u}(\mathbf{i})}(\mathbf{0})$ are irreducible with dominant main diagonal (with respect to rows). Hearon (1963) has shown that the non-null eigenvalues of this type of matrices are negative or complex with a negative real part. Therefore the roots $\lambda_{2}, \lambda_{3}, \ldots, \lambda_{\mathrm{u}(\mathrm{i})}$ have these characteristics.

\section{Kinetic equations}

From Scheme 5, from the meaning of $\mathrm{v}(\mathrm{i}), \mathrm{u}(\mathrm{i})$ and $\mathrm{w}(\mathrm{i})$ and taking into account that we consider the concentrations $\left[\mathrm{Y}_{1}\right],\left[\mathrm{Z}_{1}\right],\left[\mathrm{Z}_{2}\right], \ldots,\left[\mathrm{Z}_{\mathrm{N}}\right]$ constant (and therefore approximately equal to their initial values $\left.\left[\mathrm{Y}_{1}\right]_{0},\left[\mathrm{Z}_{1}\right]_{0},\left[\mathrm{Z}_{2}\right]_{0}, \ldots,\left[\mathrm{Z}_{\mathrm{N}}\right]_{0}\right)$, the set of $4 \mathrm{~N}$ differential equations describing the kinetic behaviour of species $X_{i}(i=1,2, \ldots, 3 N+1)$ and $Y_{j}(j=2,3, \ldots, N)$ involved in the cascade is given by the system of (non linear) differential equations (B1) in Appendix B. Assuming also that $\left[\mathrm{Y}_{2}\right],\left[\mathrm{Y}_{3}\right], \ldots,\left[\mathrm{Y}_{\mathrm{N}}\right]$ remain approximately constant during the whole course of the reaction (and therefore approximately equal to their initial values $\left.\left[\mathrm{Y}_{2}\right]_{0},\left[\mathrm{Y}_{3}\right]_{0}, \ldots,\left[\mathrm{Y}_{\mathrm{N}}\right]_{0}\right)$, the $3 \mathrm{~N}+1$ first differential equations in the system of differential equations (B1) become a set of linear differential equations with constant coefficients from which the time course of any of the species $\mathrm{X}_{1}, \mathrm{X}_{2}, \ldots \mathrm{X}_{3 \mathrm{~N}+1}$ can be obtained by analytical integration. If we are interested in the time course of any of the species $X_{i}(i=1,2, \ldots, 3 N+1)$ we only need to integrate the set of the first w(i) linear differential equations (B1) in Appendix B.

In the following, we derive the approached analytical equations giving the time course equation of any of the species $X_{i}(i=1,2, \ldots, 3 N+1)$. In the derivation of the kinetic equations the notations and definitions above must be used.

The linear system of differential equations (B3) in Appendix B admits analytical integration using any of the available mathematical method for solving a linear system of differential equations, e.g. the Laplace transform method. The analytical solutions obtained will be obviously approximate. In the main text we discuss the validity of these analytical equations.

To derive the approached analytical time course equation of any of the species $X_{i}(i=1,2, \ldots 3 N+1)$ we only need to solve the system formed by $w(i)$ first linear differential equations in (B3), because the species $\mathrm{X}_{\mathrm{w}(\mathrm{i})+1}, \ldots, \mathrm{X}_{\mathrm{w}(\mathrm{i})+2}, \ldots \mathrm{X}_{3 \mathrm{~N}+1}$ have no influence on $X_{i}$. For example, if we want to derive the time course equation of the species $X_{6}$ in a cascade we only need to solve the following set of differential equations:

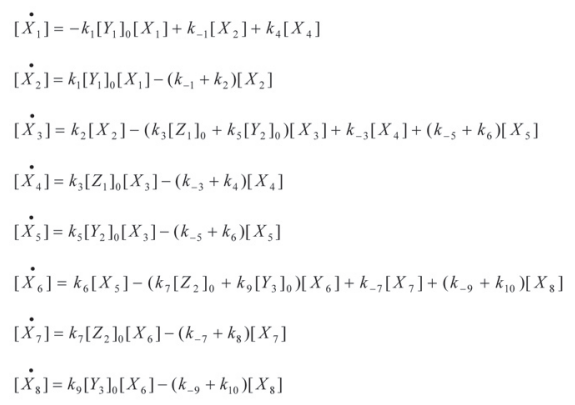

if $\mathrm{N} \geq 3(\mathrm{w}(6)=8)$ or the following set if $\mathrm{N}=2$ $(\mathrm{w}(6)=7)$ : 


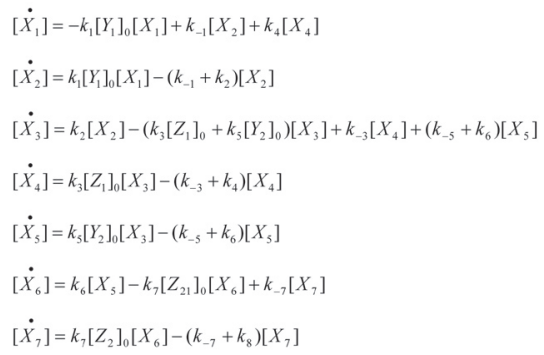

Generally, the set of $w(i)$ first equations in (B3) needed to derive the time course equation of $\mathrm{X}_{\mathrm{i}}(\mathrm{i}=1,2, \ldots, \mathrm{w}(\mathrm{i}))$ can be expressed in a matricial form as:

$\dot{\mathrm{V}}_{\mathrm{i}}=\mathrm{D}_{u(i)}(\mathbf{0}) \cdot \mathrm{V}_{i}$

If the Laplace transform is applied to both sides of Eqn. (44) and assuming that the only enzyme species $X_{i}(i=1,2, \ldots, w(i))$ present at the onset of the reaction is $X_{1}$ with a concentration $\left[X_{1}\right]_{0}$ we have:

$\mathrm{D}_{\mathrm{u}(\mathrm{i})}(\lambda) \mathrm{L}\left\{\mathrm{V}_{\mathrm{i}}\right\}=-\mathrm{V}_{\mathrm{i}, 0}$

where $\lambda$ is the operator of the Laplace transform. From eqn. (45) we have:

$L\left[\left[X_{i}\right]\right\}=\frac{(-1)^{i} d_{u(i)}(\lambda)_{i}\left[X_{1}\right]_{0}}{d_{u(i)}(\lambda)} \quad(\mathrm{i}-1,2, \ldots, \ldots,(i))$

The form of matrix $\mathrm{D}_{\mathrm{u}(\mathrm{i})}(\lambda)_{\mathrm{i}}$ permits its determinant, i.e. $d_{u(i)}(\lambda)_{i}$, to be expressed as the product: $\mathrm{d}_{\mathrm{u}(\mathrm{i})}(\lambda)_{\mathrm{i}}=\mathrm{r}_{1}(\lambda) \cdot \mathrm{r}_{2}(\lambda) \cdots \mathrm{r}_{\mathrm{u}(\mathrm{i})-1}(\lambda) \cdot \mathrm{r}_{\mathrm{u}(\mathrm{i})}(\lambda)_{\mathrm{i}}$

where $r_{1}(\lambda), r_{2}(\lambda), \ldots ., r_{u(i)-1}(\lambda)$ are given by Eqn. (33) with $j=1,2, \ldots u(i)-1$ and $r_{u(i)}(\lambda)_{i}$ is given either by Eqn (34) if $\mathrm{u}(\mathrm{i})=1$ or by Eqns. (35) and (36) if $\mathrm{u}(\mathrm{i})>1$, i.e.

$d_{u(i)}(\lambda)_{i}= \begin{cases}(-1)^{1+i}\left(b_{1,4}(i) \lambda^{4}+b_{1,3}(i) \lambda^{3}+b_{1,2}(i) \lambda^{2}+b_{1,1}(i) \lambda+b_{1,0}(i)\right) & \text { if } u(i)=1 \\ (-1)^{(i)+i+i f}\left(b_{1,1} \lambda+b_{1,0}\right)\left(b_{2,1} \lambda+b_{2,0}\right) \cdots\left(b_{u(i), 1}(i) \lambda+b_{u(i), 0}(i)\right) & \text { if } u(i)>1\end{cases}$

in the first of the above Equations (48) it has been taken into account that $\mathrm{v}(1)=1$.

Equations (48) shows that $\mathrm{d}_{\mathrm{u}(\mathrm{i})}(\lambda)_{\mathrm{i}}$ is a polynomial with the degree $\mathrm{w}(\mathrm{i})-1$ if $\mathrm{u}(\mathrm{i})=1, \mathrm{u}(\mathrm{i})$ if 1 $<\mathrm{u}(\mathrm{i})<\mathrm{N}$ or if $\mathrm{u}(\mathrm{i})=\mathrm{N}$ and $\mathrm{i}=3 \mathrm{~N}$ and, finally, $\mathrm{u}(\mathrm{i})-1$ if $u(i)=N$ and $i=3 N+1$ (because $\left.b_{N}(3 N+1)=0\right)$. Since the degree of the polynomial in the numerator of Eqn. (46) is less than that of the denominator (remember that the degree of $\mathrm{d}_{\mathrm{u}(\mathrm{i})}(\lambda)$ is $\mathrm{w}(\mathrm{i})$ and that $w(i)=3 u(i)+1)$, the right side of Eqn. (46) can, with the use of Eqn. (41), be expressed as:

$\frac{(-1)^{i} d_{u(i)}(\lambda)_{i}\left[X_{1}\right]_{0}}{d_{u(i)}(\lambda)}=\frac{A_{i, 1}}{\lambda}+\sum_{h=2}^{w(i)} \frac{A_{i, h}}{\lambda-\lambda_{h}}$

The decomposition in partial fractions shown in Eqn. (48) requires that the roots $\lambda_{2}, \lambda_{3}, \ldots, \lambda_{\mathrm{w}(\mathrm{i})}$ are assumed to be distinct. When the inverse of the Laplace transform is applied to both sides of Eqn. (49) we obtain the concentration of $X_{i}(i=1,2, \ldots, w(i))$ :

$\left[X_{i}\right]=A_{i, 1}+\sum_{h=2}^{\mathrm{w}(i)} A_{i, h}{ }^{\lambda_{i, t}} \quad \quad(\mathrm{i}=1,2, \ldots, \mathrm{w}(\mathrm{i}))$
Eqn. (49) also yields:

$A_{i, 1}=\frac{(-1)^{i+1} d_{u(i)}(0)_{i}\left[X_{1}\right]_{0}}{\lambda_{2} \lambda_{3} \cdots \lambda_{w(i)}}$

and

$$
A_{i, h}=\frac{(-1)^{i} d_{u(i)}\left(\lambda_{h}\right)_{i}\left[X_{1}\right]_{0}}{\lambda_{h} \prod_{\substack{p=2 \\ p=2}}^{w p h}\left(\lambda_{p}-\lambda_{h}\right)}
$$$$
(\mathrm{h}=2,3, \ldots, \mathrm{w}(\mathrm{i}))
$$

From Eqns. (47) and (33)-(36) we have:

$\mathrm{d}_{\mathrm{u}(\mathrm{i})}(0)_{\mathrm{i}}=(-1)^{\mathrm{v}(\mathrm{i})+\mathrm{i}+\mathrm{f}} \mathrm{b}_{1,0} \cdot \mathrm{b}_{2,0} \cdots \mathrm{b}_{\mathrm{u}(\mathrm{i})-1,0} \cdot \mathrm{b}_{\mathrm{u}(\mathrm{i}), 0}(\mathrm{i}) \quad(\mathrm{f}=0$ if $\quad \mathrm{u}(\mathrm{i})<\mathrm{N}$ else $f=1$ )

and from the polynomial theory and Eqns. (30)-(32) we obtain the following relations:

$\lambda_{2} \lambda_{3} \lambda_{4} \lambda_{5}=a_{1,0}$

$\lambda_{\mathrm{v}(\mathrm{j})} \cdot \lambda_{\mathrm{v}(\mathrm{j})+1} \cdot \lambda_{\mathrm{w}(\mathrm{j})}=-a_{\mathrm{j}, 0} \quad(\mathrm{j}=2,3, \ldots, \mathrm{N}-1)$

$\lambda_{3 \mathrm{~N}} \cdot \lambda_{3 \mathrm{~N}+1}=a_{\mathrm{N}, 0}$

From Eqns. (54) and (55) we have:

$\lambda_{2} \lambda_{3} \cdots \lambda_{\mathrm{w}(\mathrm{i})}=(-1)^{\mathrm{w}(\mathrm{i})-1} a_{1,0} \cdot a_{2,0} \cdots a_{\mathrm{u}(\mathrm{i}), 0}$

Equations (53) and (57) are inserted into Eqn. (51) to yield:

$A_{i, 1}=\frac{b_{1,0} \cdot b_{2,0} \cdots b_{u(i)-1,0} \cdot b_{u(i), 0}(i)\left[X_{1}\right]_{0}}{a_{1,0} \cdot a_{2,0} \cdots a_{u(i), 0}}$

where it has been taken into account that $v(i)+w(i)+f$ is always even.

Eqn. (53) is inserted into Eqn. (52) to give:

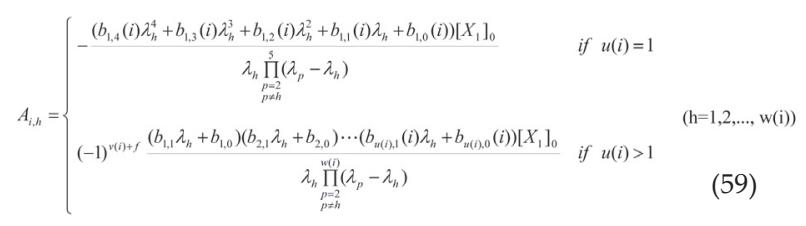

Note that in order to obtain analytical expressions of the roots $\lambda_{1}, \lambda_{2}, \ldots, \lambda_{\mathrm{w}(\mathrm{i})}$ involved in the kinetic equations of the model [see Eqns. (38)-(40)] it is always necessary to solve one quartic equation, as well as $\mathrm{N}-2$ cubic equations (if $\mathrm{N} \geq 3$ ) and one quadratic equation (if $\mathrm{N} \geq 2$ ). In Appendix $C$ we summarise an algebraic procedure for deriving analytical expressions of the roots of both cubic (Cardano's method) and quartic equations (Ferrari's method).

\section{Example}

We consider a tricyclic cascade system, which is given by Scheme 4 with $\mathrm{N}=3$. We assume that we are interested in obtaining the kinetic equations of species $X_{6}$. According to Table $1, \mathrm{u}(6)=2, \mathrm{v}(6)=$ 6 and $w(6)=8$. Therefore according to Eqn. (49) we have:

$\left[X_{6}\right]=A_{6,1}+\sum_{h=2}^{8} A_{6, h} e^{\lambda_{h, t}}$

in which $\lambda_{2}, \lambda_{3}, \lambda_{4}$ and $\lambda_{5}$ are the non-null roots of the polynomial $g_{1}(\lambda)$ (see Eqn. (30)), i.e. the roots of 
the polynomial $\lambda^{4}+a_{1,3} \lambda^{3}+a_{1,2} \lambda^{2}+a_{1,1} \lambda+a_{1,0^{\prime}}$ whereas $\lambda_{6}, \lambda_{7}$ and $\lambda_{8}$ are the roots of the polynomial in Eqn. (31) with $j=2$. Therefore according to Eqns. (A5)-(A7) in Appendix A, the coefficients in Eqn. (31) are:

$a_{2,2}=k_{-7}+k_{8}+k_{-9}+k_{10}+k_{7}\left[\mathrm{Z}_{2}\right]_{0}+k_{9}\left[\mathrm{Y}_{3}\right]_{0}$

$a_{2,1}=\left(k_{-7}+k_{8}\right)\left(k_{-9}+k_{10}\right)+k_{7}\left(k_{8}+k_{-9}+k_{10}\right)\left[Z_{2}\right]_{0}+k_{9}\left(k_{-7}+\right.$ $\left.k_{8}\right)\left[\mathrm{Y}_{3}\right]_{0}$

$a_{2,0}=k_{7} k_{8}\left(k_{-9}+k_{10}\right)\left[Z_{2}\right]_{0}$

Eqn. (50) yields, with $\mathrm{i}=6$ and $\mathrm{u}(6)=2$ :

$A_{6,1}=\frac{b_{1,0} \cdot b_{2,0}(6)\left[X_{1}\right]_{0}}{a_{1,0} \cdot a_{2,0}}$

Since $5<\mathrm{i}<3 \mathrm{~N}$ (i.e. $5<6<9$, see Eqn. (35)) and $\mathrm{i}=\mathrm{v}(\mathrm{i})$ (i.e. $6=\mathrm{v}(2)$, see Eqn. (A32)), the expression for $b_{2,0}(6)$ is given by the first of Eqns. (A32) for $\mathrm{u}(\mathrm{i})=2$, i.e.:

$b_{2,0}(6)=\left(k_{-7}+k_{8}\right)\left(k_{-9}+k_{10}\right)$

The expression $b_{1,0}$ is given by Eqn. (A11), whereas the expression for $a_{2,0}$ is given by Eqn. (A7) (with $\mathrm{j}=2$ ), i.e.:

$a_{2,0}=k_{7} k_{8}\left(k_{-9}+k_{10}\right)\left[Z_{2}\right]_{0}$

The insertion of Eqns. (A11), (65) and (66) into Eqn. (64) finally yields:

$A_{6,1}=\frac{k_{1} k_{2} k_{5} k_{6}\left(k_{-3}+k_{4}\right)\left(k_{-7}+k_{8}\right)\left[Y_{1}\right]_{0}\left[X_{1}\right]_{0}}{a_{1,0} k_{7} k_{8}\left[Z_{2}\right]_{0}}$

where $a_{1,0}$ is given in Eqn. (A4).

Hence, according to Eqn. (59) for the values of $\mathrm{i}, \mathrm{u}(\mathrm{i}), \mathrm{w}(\mathrm{i})$ and $\mathrm{f}$ of $6,2,8$ and 0 , respectively, $\mathrm{A}_{6, \mathrm{~h}}(\mathrm{~h}=2,3, \ldots, 8)$ is:

$$
A_{6, h}=\frac{\left(b_{1,1} \lambda_{h}+b_{1,0}\right)\left(b_{2,1}(6) \lambda_{h}+b_{2,0}(6)\right)\left[X_{1}\right]_{0}}{\lambda_{h} \prod_{\substack{p=2 \\ p \neq h}}^{8}\left(\lambda_{p}-\lambda_{h}\right)} \quad(\mathrm{h}=2,3, \ldots, 8)
$$

Where $b_{1,1}$ and $b_{1,0}$ are given by Eqns. (A10) and (A11), respectively, whereas $b_{2,1}(6)$ is given by the first of Eqns. (A31) and $b_{2,0}(6)$ by the first of Eqns. (A32), i.e.:

$$
\begin{aligned}
& b_{2,1}(6)=k_{-9}+k_{10} \\
& \mathrm{~b}_{2,0}(6)=\left(k_{-7}+k_{8}\right)\left(k_{-9}+k_{10}\right)
\end{aligned}
$$

Therefore the concentration of the enzyme species $\mathrm{X}_{6}$ as a function of time is given by the seven-exponential Eqn. (60). The kinetic equations of any of the other enzyme species $X_{i}(i=1,2, \ldots, 10)$ are obtained analogously. Note that for $X_{1}, X_{2}, \ldots, X_{5}$ four-exponential equations are obtained; whereas $X_{6}$ $X_{7}$ and $X_{8}$ yield seven-exponential equations. For $X_{9}$ and $X_{10}$ eight-exponential ones are obtained.

\section{RESULTS AND DISCUSSION}

We performed a complete kinetic analysis of the general model of multicyclic cascades shown in Scheme 1, under a minimal set of assumptions, to obtain the explicit analytical solution of the corresponding system of differential equations which is required for the derivation of the kinetic equations, Eqn. (50) and subsequent expressions. These equations are valid for the whole course of the reaction, i.e. for both the transient phase and the kinetic steady state. Previously, only a kinetic analysis of the steady state of Scheme 1 has been carried out (Chock \& Stadtman, 1977; 1980) under the same assumptions 1-3 used here and other ones that make the steady state results more restrictive than the corresponding ones obtained here.

Equation (50), which describes the time dependence of the variation of the concentrations of the species $X_{i}(i=1,2, \ldots, 3 N+1)$ contains a number of exponential terms, w(i)-1, which depends upon the i-value. According to this equation the enzyme species $X_{\mathrm{w}(\mathrm{i})+1}, \mathrm{X}_{\mathrm{w}(\mathrm{i})+2}, \ldots, \mathrm{X}_{3 \mathrm{~N}+1}$ do not influence the behaviour of species $X_{i}$, as expected.

Assumption 1 of a rapid equilibrium in the reversible steps in which the allosteric effectors are involved during the whole course of the reaction means that these steps reach the equilibrium practically at the onset of the reaction, i.e. from $t \approx 0$. According to Varón et al. (2000) that requires that both the pseudofirst rate constant $k_{j}^{\prime}\left[e_{j}\right] \quad(j=1,2, \ldots$ $\mathrm{N}+1$ ) (because from assumption $3\left[\mathrm{e}_{\mathrm{j}}\right]$ is constant) and the first rate constant $k_{-j}^{\prime}(j=1,2, \ldots N+1)$ involved in each of the reversible steps (note that $K_{j}^{\prime}=k_{-j}^{\prime} l$ $k_{\mathrm{j}}$ ) in which an allosteric effector binds the modifier enzyme are much higher than all of the other ones involved in the cascade. Thus, by deriving our equations we have implicitly presumed (through assumptions 1 and 3) that all of the modification steps (reversible or not) are much slower than those of activation and deactivation of the modifier enzymes. Obviously, in a cascade there must be a step slower than the other ones, i.e. the rate-limiting step. Nevertheless, our analysis is not based on any rate-limiting step, but on the analytical integration of the set of differential equations (B1) after using assumptions 1-4 which linearises it. A good general discussion about the time scales of enzyme regulatory mechanisms is provided by Ottaway (1988).

\section{The steady state equation}

Because the roots $\lambda_{2}, \lambda_{3} \ldots, \lambda_{\mathrm{w}(\mathrm{i})}$ are negative or complex with a negative real part, the exponential term in Eqn. (50) can be neglected beginning from a reaction time high enough $(t \rightarrow \infty)$ that the steady state can be assumed reached. If in Eqn. (50) we make $t$ infinite, we have for the concentration of species $X_{i}$ at the steady state, $\left[X_{i}\right]_{S s}$ :

$\left[X_{i}\right]_{S S}=A_{i, 1} \quad(\mathrm{i}=1,2, \ldots, 3 \mathrm{~N}+1)$ 
i.e. all the species $X_{i}$ reach a constant concentration given by Eqn. (72) in the steady state, which allows Eqn. (50) to be rewritten as:

$\left[X_{i}\right]=\left[X_{i}\right]_{s s}+\sum_{h=2}^{w(i)} A_{i, h} e^{\lambda_{h} t} \quad(\mathrm{i}=1,2, \ldots, \mathrm{w}(\mathrm{i}))$

a time course equation for the whole course of the reaction, i.e. for the transient phase and the steady state, at which Eqn. (72) becomes:

$\left[X_{i}\right]=\left[X_{i}\right]_{s S} \quad$ (steady state; $\mathrm{i}=1,2, \ldots, \mathrm{w}(\mathrm{i})$ )

From Eqns. (71) and (58), $\left[\mathrm{X}_{\mathrm{i}}\right]_{\mathrm{sS}}$ is given by:

$\left[X_{i}\right]_{s s}=\frac{b_{1,0} \cdot b_{2,0} \cdots b_{u(i)-1,0} \cdot b_{u(i), 0}(i)\left[X_{1}\right]_{0}}{a_{1,0} \cdot a_{2,0} \cdots a_{u(i), 0}}$

\section{The fractional modification}

An interesting parameter related to cyclic cascades is the fractional modification of the active interconvertible enzyme (Shacter et al., 1986). The active forms of the interconvertible enzymes $\mathrm{I}_{1}, \mathrm{I}_{2}, \ldots, \mathrm{I}_{\mathrm{N}}$ in the model (see Schemes 1 and 2) are denoted by us as $X_{3}, X_{6}, \ldots, X_{3 N}$, i.e. $X_{3 n}(n=1,2, \ldots, N)$. In the following we refer to the fractional modification of the active interconvertible enzyme $I_{n}(n=1,2, \ldots, N)$ as $F M_{n}$. In our notation it is defined as:

$F M_{n}= \begin{cases}{\left[X_{3}\right] /\left[X_{1}\right]_{0}} & \text { if } n=1 \\ {\left[X_{3 n}\right] /\left[Y_{n}\right]} & \text { if } n>1\end{cases}$

If Eqn. (50) is inserted into Eqn. (75) and account is taken that from the definition of $u(i)(i=1,2, .$. , $3 N+1), u(3 n)=n$, then one obtains:

$F M_{n}=\left(F M_{n}\right)_{s s}+\sum_{h=2}^{w(n)} B_{n, h} e^{\lambda_{n} t}$

where, according to general Eqns. (75) and (74), setting $\mathrm{i}=3 \mathrm{n}$ and taking into account that $\mathrm{u}(3 n)=n$ :

$\left(F M_{n s:}= \begin{cases}b_{1,0}(3) & \text { if } n=1 \\ a_{1,0} & \\ a_{1,0} \cdot b_{20} \cdot b_{n-10} \cdot b_{n, 0}(3 n)\left[X_{1}\right] 0 & \text { if } n>1 \\ a_{1,0} \cdot a_{2,0} \cdot a_{n, 0}\left[Y_{n}\right] & \end{cases}\right.$

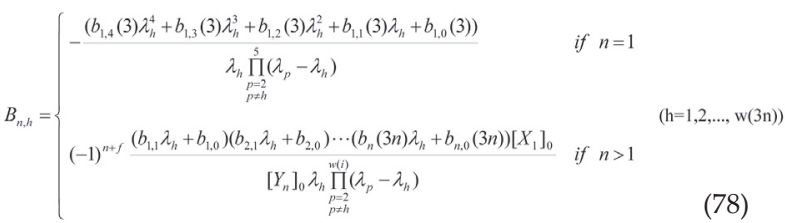

$\left(\mathrm{FM}_{\mathrm{n}}\right)_{\mathrm{ss}}$ in Eqn. (76) is the fractional modification in the steady state of the interconvertible enzyme $\mathrm{I}_{\mathrm{n}}$ $(\mathrm{n}=1,2, \ldots, \mathrm{N})$.

For example, for an open tricyclic cascade, the fractional modification at the steady state of $\mathrm{I}_{3}$, i.e. $\left(\mathrm{FM}_{3}\right)_{\mathrm{sS}^{\prime}}$ is according to Eqn. (77), taking into account the expressions in Appendix A for the coefficients $b_{1,0}, b_{2,0}, b_{3,0}(9), a_{1,0}, a_{2,0}$ and $a_{3,0}$ and considering that $\mathrm{N}=3$, and after some rearrangement:

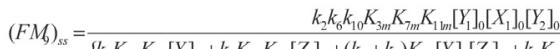

$=\overline{\left\{k_{2} K_{3 m} K_{5 m}\left[Y_{1}\right]_{0}+k_{4} K_{1 m} K_{5 m}\left[Z_{1}\right]_{0}+\left(k_{2}+k_{4}\right) K_{5 m}\left[Y_{1}\right]_{0}\left[Z_{1}\right]_{0}+k_{2} K_{3 m}\left[Y_{1}\right]_{0}\left[Y_{2}\right]_{0}\right\} k_{g} k_{12} K_{9 m}\left[Z_{2}\right]_{0}\left[Z_{3}\right]_{0}}$

where $K_{\mathrm{jm}}(\mathrm{j}=1,2,3,5,7,9,11)$ means the Michaelis constant $\left(k_{-\mathrm{j}}+k_{\mathrm{j}+1}\right) / k_{\mathrm{j}}$.

\section{Validity of our kinetic analysis}

We have obtained, for the first time, time course equations giving the concentration of all of the species $X_{i}(i=1,2, \ldots, 3 N+1)$ involved in an open multicyclic cascade system from $t=0$ to the steady state $(t \rightarrow \infty)$.

To obtain these equations we used assumptions 1-3 (which coincide with some of the assumptions used in previous contributions of other authors regarding the steady state analysis only) which allowed us to set $\left[\mathrm{Y}_{1}\right] \approx\left[\mathrm{Y}_{1}\right]_{0}$ and $\left[\mathrm{Z}_{\mathrm{j}}\right] \approx\left[\mathrm{Z}_{\mathrm{j}}\right]_{0}$ $(\mathrm{j}=1,2, \ldots, N)$. Moreover, we used assumption 4 that the concentration of the inactive enzyme species $\mathrm{Y}_{2}, \mathrm{Y}_{3^{\prime}}, \ldots, \mathrm{Y}_{\mathrm{N}}$ (i.e. unmodified enzymes $\mathrm{I}_{2, \mathrm{i}^{\prime}}, \mathrm{I}_{3, \mathrm{i}^{1}}, \ldots, \mathrm{I}_{\mathrm{N}, \mathrm{i}}$ ) remain approximately constant during the whole course of the reaction, i.e. we assume that $\left[Y_{j}\right] \approx$ $\left[Y_{j}\right]_{0}(j=2,3, \ldots, N)$. These four assumptions allowed us to linearise the corresponding system of differential equations describing the kinetic behaviour of the system indicated in Scheme 5. Note that all four assumptions are of the same, operational nature, and were required simply to reach the goal - linearisation of the system.

Assumptions 1-3 are widely used in contributions concerning cascade systems. Assumption 4 requires some discussion. The fulfilment of assumption 4 implies that, at any time, the concentration of species $Y_{j}(j=2,3, \ldots, N)$ must be approximately equal to its initial concentration $\left[Y_{j}\right]_{0}(j=2,3, \ldots, N)$. From the system of differential equations in (B1) it is easy to see that all of the species $X_{i}(i=1,2, \ldots, 3 N+1)$ and $Y_{j}(j=2,3, \ldots ., N)$ will reach a steady state in which their conversion rates are null and their concentrations $\left[Y_{j}\right]_{\mathrm{ss}}$ remain constant. This result is shown in Figs. 1-4 in which we plot simulated time course curves for a tricyclic cascade obtained from numerical integration of Eqns. (B2).

Obviously, the assumed constancy of $\left[\mathrm{Y}_{\mathrm{j}}\right]$ $(\mathrm{j}=2,3, \ldots, \mathrm{N})$ in an assay requires that:

$\left[\mathrm{Y}_{\mathrm{j}}\right]_{\mathrm{ss}} \approx\left[\mathrm{Y}_{\mathrm{j}}\right]_{0} \quad(\mathrm{j}=2,3, \ldots, \mathrm{N})$

Thus, the more the condition (80) is fulfilled, the more accurate are the analytically approached equations. The two coupled reactions in which $Y_{j}$ is involved are (see Scheme 4):

$\left.\begin{array}{l}X_{3(j-1)}+Y_{j} \rightleftarrows X_{3 j-1} \rightarrow X_{3 j}+X_{3(j-1)} \\ Z_{j}+X_{3 j} \rightleftarrows X_{3 j+1} \rightarrow Y_{j}+Z_{j}\end{array}\right\} \quad(j=2,3, \ldots, N)$

Because $X_{3}$ can reach, at a maximum, the value $\left[X_{1}\right]_{0}$ and $X_{3(j-1)}(j=3,4, \ldots, N)$ could reach, at a maximum, the value $\left[\mathrm{Y}_{\mathrm{j}-1}\right]_{0}(\mathrm{j}=3,2, \ldots, \mathrm{N})$, an experimental 
way of ensuring that condition (80) is fulfilled consists in setting:

$\left[\mathrm{X}_{1}\right]_{0} \ll\left[\mathrm{Y}_{2}\right]_{0} \ll\left[\mathrm{Y}_{3}\right]_{0} \ll \cdots \ll\left[\mathrm{Y}_{\mathrm{N}}\right]_{0}$

Condition (82) is the strict condition. Nevertheless it is too strong. Normally, condition

$\left[\mathrm{X}_{1}\right]_{0} \ll\left[\mathrm{Y}_{2}\right]_{0} \leq\left[\mathrm{Y}_{3}\right]_{0} \leq \cdots \leq\left[\mathrm{Y}_{\mathrm{N}}\right]_{0}$

is sufficient as numerical integration shows (see Figs. 2-4).

There are different contributions providing suitable software for numerical integration of differential equation systems describing the kinetic behaviour of an enzyme system such as MetaModel (Cornish-Bowden \& Hofmeyr, 1991), SCAMP (Sauro, 1993), Gepasi (Mendes, 1997), DBSolve (Goryanin et al., 1999) and Jarnac (Sauro, 2000). Nevertheless, for this task we used our own software WES corresponding to the contribution by García-Sevilla et al. (1999) which has been specifically developed for enzyme reactions.

In Figs. 1-4 we tested the validity of our results by comparing simulated progress curves for a tricyclic cascade with plots of the corresponding equations obtained as explained previously in the example. The simulated progress curves were obtained by numerical integration of the system of differential equations (B2). Note the good agreement between the simulated progress curves and those obtained from our analysis when condition (82) or (83) are observed. In Table 2 we obtain and compare quantitatively, by means of the suggested parameter goodness of $\left[X_{j}\right](j=3,6,9)$ (in the following $g(j)(j=1,2,3)$ which indicates the goodness of the analytical approach in different cases corresponding to Figs. 1-4. We define this fitting parameter as:

$g(j)=\frac{\sum_{k=1}^{g} \frac{\left|r_{j, k}-s_{j, k}\right|}{s_{j, k}}}{Q} \quad(\mathrm{j}=3,6,9)$

where $\mathrm{Q}$ is the number of time points used in the simulation, $\mathrm{k}$ is an index which takes the values $1,2, \ldots ., Q, \quad r_{j, k}$ is the value of $\left[X_{j}\right]$ at the time corresponding to $\mathrm{k}$, i.e. at time $t_{\mathrm{k}}\left(t_{1}=0, \ldots ., t_{\mathrm{Q}}=T=\right.$ reaction time used) obtained from the analytical solutions and $s_{j, k}$ is the value of $\left[X_{j}\right]$ at time $t_{k}$ obtained from the simulation. Note that $g(j)(j=3,6,9)$ is the mean of the relative errors committed when at each time $t_{\mathrm{k}}$ the value for $\left[\mathrm{X}_{\mathrm{j}}\right](\mathrm{j}=3,6,9)$ obtained from the analytical approach is taken instead of that from the simulation.

The kinetic equations obtained by us are valid if initial condition (82) or the less restrictive condition (83) are fulfilled, both easy to reach experimentally. Moreover, they are also applicable at reaction times short enough so that the $\left[\mathrm{Y}_{2}\right],\left[\mathrm{Y}_{3}\right], \ldots\left[\mathrm{Y}_{\mathrm{N}}\right]$ values do not considerably differ from the initial values and, therefore, can be considered approximately constant (see inset of Fig. 1). Briefly, our analysis is applica-

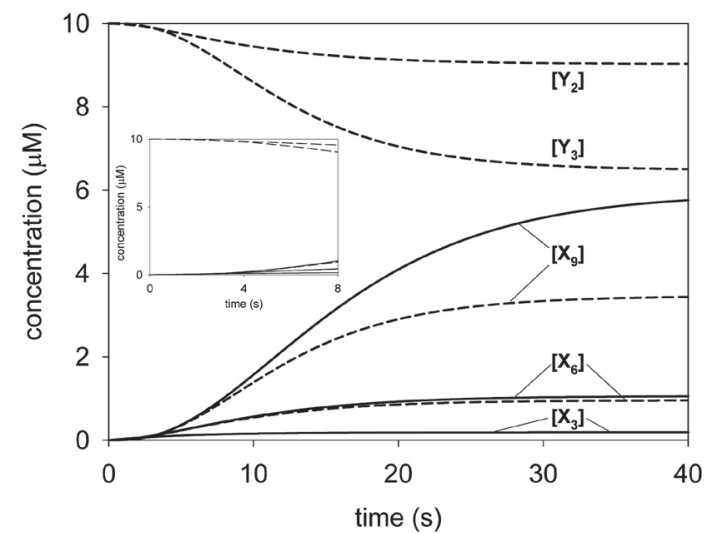

Figure 1. Time progress curves in an open tricyclic cascade under the indicated particular set of values of the initial concentrations and rate constants.

(-) Curves obtained from plot of eqn. (50) for $X_{3}, X_{6}$ and $X_{9}$ and $N=3$. (- - -) Simulated time progress curves of $Y_{2}$, $\mathrm{Y}_{3}, \mathrm{X}_{3}, \mathrm{X}_{6}$ and $\mathrm{X}_{9}$ obtained by numerical integration of the set of differential equations (B1). In the inset figure the kinetic behaviour at the onset of the reaction when neither is amplified. The values of the rate constants and initial concentrations were: $k_{1}=10^{5} \mathrm{M}^{-1} \mathrm{~s}^{-1}, k_{-1}=4 \mathrm{~s}^{-1}, k_{2}=1000$ $\mathrm{s}^{-1}, k_{3}=10^{5} \mathrm{M}^{-1} \mathrm{~s}^{-1}, k_{-4}=4 \mathrm{~s}^{-1}, k_{4}=10 \mathrm{~s}^{-1}, k_{5}=10^{5} \mathrm{M}^{-1} \mathrm{~s}^{-1}$, $k_{-5}=4 \mathrm{~s}^{-1}, \quad k_{6}=1000 \mathrm{~s}^{-1}, \quad k_{7}=10^{5} \mathrm{M}^{-1} \mathrm{~s}^{-1}, \quad k_{-7}=4 \mathrm{~s}^{-1}, k_{8}=$ $10 \mathrm{~s}^{-1}, k_{9}=10^{5} \mathrm{M}^{-1} \mathrm{~s}^{-1}, k_{-9}=4 \mathrm{~s}^{-1}, k_{10}=1000 \mathrm{~s}^{-1}, k_{11}=10^{5}$ $\mathrm{M}^{-1} \mathrm{~s}^{-1}, k_{-11}=4 \mathrm{~s}^{-1}, k_{12}=10 \mathrm{~s}^{-1}, \quad\left[\mathrm{X}_{1}\right]_{0}=10^{-5} \mathrm{M}, \quad\left[\mathrm{Y}_{2}\right]_{0}=10^{-5}$ M, $\left[Y_{3}\right]_{0}=10^{-5} \mathrm{M},\left[\mathrm{X}_{2}\right]_{0}=\left[\mathrm{X}_{3}\right]_{0}=\left[\mathrm{X}_{4}\right]_{0}=\left[\mathrm{X}_{5}\right]_{0}=\left[\mathrm{X}_{6}\right]_{0}=\left[\mathrm{X}_{7}\right]_{0}$ $=\left[X_{8}\right]_{0}=\left[X_{9}\right]_{0}=\left[X_{10}\right]_{0}=0$. Moreover $[E]=K_{1}^{\prime}=5 \times 10^{-6}$ $\mathrm{M},\left[\mathrm{e}_{1}\right]=3.5 \times 10^{-8} \mathrm{M}$ (therefore, according to Eqn. (5) and the notation used, $\left.\left[Y_{1}\right]_{0}=3.47567 \times 10^{-8} \mathrm{M}\right)$ and $K_{2}^{\prime}=K^{\prime}$ $=K_{4}^{\prime}=\left[\mathrm{e}_{2}\right]=\left[\mathrm{e}_{3}\right]=\left[\mathrm{e}_{4}\right]=\left[\mathrm{R}_{1}\right]=\left[\mathrm{R}_{2}\right]=\left[\mathrm{R}_{3}\right]=5 \times 10^{-6} \mathrm{M}$ (therefore, according to Eqn. (6) and the notation used it is $\left.\left[Z_{1}\right]_{0}=\left[Z_{2}\right]_{0}=\left[Z_{3}\right]_{0}=2.5 \times 10^{-6} \mathrm{M}\right)$.

ble at any reaction time if condition (82) or (83) are fulfilled and in any case at the onset of the reaction where condition (80) is always fulfilled. The advantage of disposing of the time course equations is the possibility to suggest an experimental design and a kinetic data analysis based on these equations that allows characterisation of the system, i.e. estimation of individual or target kinetic parameters (which are independent of the initial conditions). Once the kinetic parameters have been estimated, the kinetic behaviour of the system under other initial conditions can learned, e.g. by numerical simulation.

Table 2 shows the goodness of $\left[X_{3}\right],\left[X_{6}\right]$ and $\left[X_{9}\right]$ corresponding to each of the Figs. 1-4. Note that in cases 2, 3 and 4, in which conditions (82) or (83) are fulfilled, the $\mathrm{g}(\mathrm{j})$ values are low as well as in case 1 (inset) in which condition (80) is observed in the considered time ( $8 \mathrm{~s})$ and that for the same set of values of the rate constants and initial concentrations (i.e. for any of the cases 1-4, the goodness of our analysis decreases in the order $\left[X_{3}\right],\left[X_{6}\right],\left[X_{9}\right]$ and that for the different cases, the goodness of the approached equation for $\left[X_{j}\right](j=1,2,3)$ is the better the more conditions (82) or (83) are accomplished. Below, we introduce a limit parameter, G, to quantify the limits of our approached solutions. 

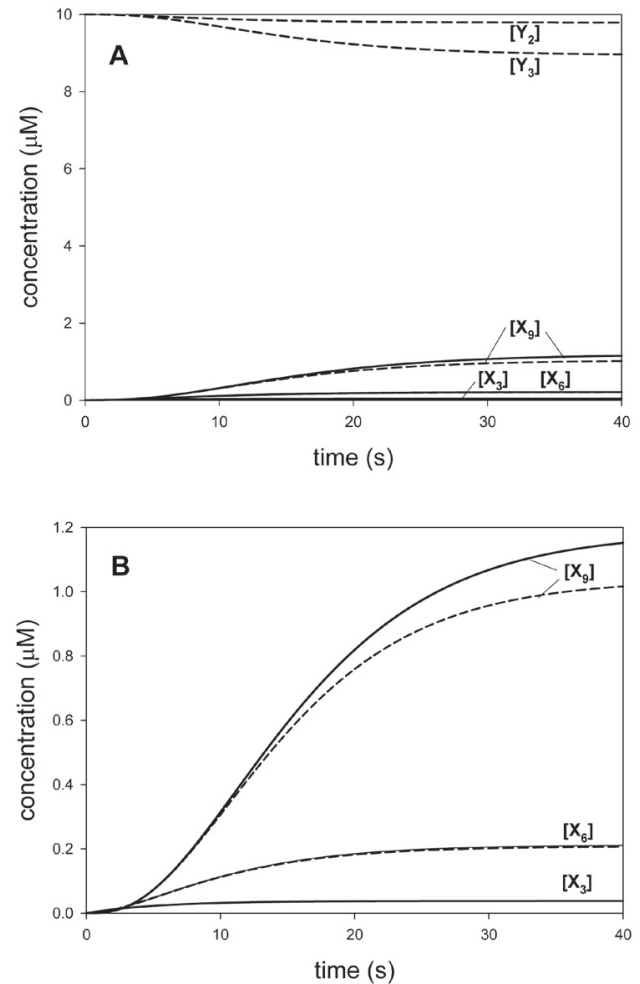

Figure 2. Time progress curves in an open tricyclic cascade under the same set of values as in Fig. 1 except that the value used for $\left[X_{1}\right]_{0}$ was $2 \times 10^{-6} \mathrm{M}$.

(A). (-) Curves obtained from plot of Eqn. (50) for $X_{3}, X_{6}$ and $X_{9}$ and $N=3$. (- - ) Simulated time progress curves of $Y_{2}, Y_{3}, X_{3}, X_{6}$ and $X_{9}$ obtained by numerical integration of the set of differential equations (B1). (B). The same curves for $\mathrm{X}_{3}, \mathrm{X}_{6}$ and $\mathrm{X}_{9}$ as in (A) but using a more suitable scale.

The general kinetic equations obtained here are valid for any $\mathrm{N}$-cyclic cascade system, in which $\mathrm{N} \geq 2$, i.e. for all multicyclic cascades which fit our model. An analogous analysis has already been done (Varón \& Havsteen, 1990) for monocyclic cascade systems $(\mathrm{N}=1)$. If the general equations presented here are applied to the case in which $\mathrm{N}$ $=1$, then $0 / 0$ indeterminations arise, the solution of which gives the same results as those obtained from the individualised study of monocyclic cascades systems.

\section{Limits of applicability of the postulated model}

The limits of applicability of the postulated model are precisely those for which assumptions 1 4 are no more fulfilled. Extensive discussions about the fulfilment of assumptions 1-3 have already been made by those authors who carried out the kinetic analysis of multicyclic enzyme cascades (Chock \& Stadtman, 1977).

In enzyme kinetics it is frequent to assume an approximately constant concentration of a ligand species (i.e. substrate, activator or inhibitor) during the assayed reaction time in order to be able to de-

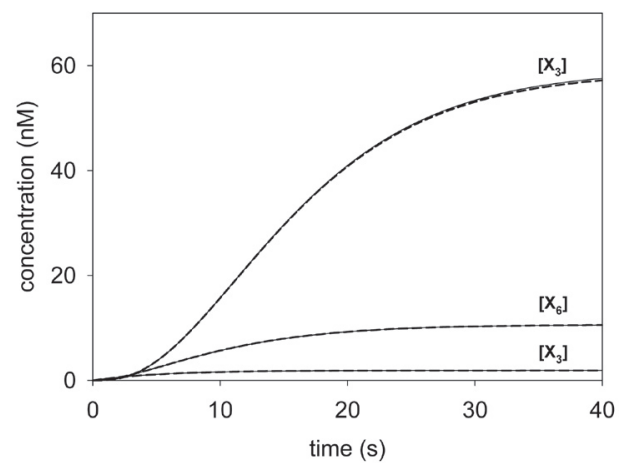

Figure 3. Time progress curves in an open tricyclic cascade under the same set of values as in Fig. 1 except that the value used for $\left[X_{1}\right]_{0}$ was $10^{-7} \mathrm{M}$.

(-) Curves obtained from plot of Eqn. (50) for $X_{3}, X_{6}$ and $X_{9}$ and $N=3$. (- - ) Simulated time progress curves of $X_{3}$ $X_{6}$ and $X_{0}$ obtained by numerical integration of the set of differential equations (B1).

rive approached analytical kinetic equations, which will remain valid while the assumption of the constancy of the ligand concentration prevails (Segel, 1975; Cornish-Bowden, 1995). Quantitatively, variation of the ligand concentration of $5 \%$ in comparison with its initial value is normally accepted as the limit of the validity of the approached equations (Segel, 1975). Obviously, approached kinetic equations could also be considered valid for a drop in the ligand concentration higher than $5 \%$, but the accuracy of the analytical solutions results are the worse the more variation is allowed. A high decrease of the ligand concentration makes advisable to use the Michaelis Integrated Method (Segel, 1975).

Let us fix an upper limit $G$ (expressed per unity of concentration) in the variation of the concentration of any of the ligand species initially present in an enzyme system under which we accept the validity of the approached analytical equations (e.g. G $=0.05)$. In our analysis, in each cycle the specie $Y_{j}$

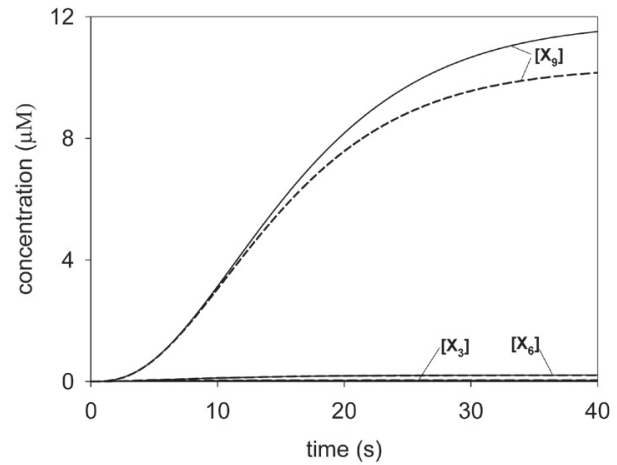

Figure 4. Time progress curves in an open tricyclic cascade under the same set of values as in Fig. 1 except that the values used for $\left[X_{1}\right]_{0}$ and $\left[Y_{3}\right]_{0}$ were $2 \times 10^{-6} \mathrm{M}$ and $10^{-4} \mathrm{M}$, respectively.

(-) Curves obtained from plot of Eqn. (50) for $X_{3}, X_{6}$ and $X_{9}$ and $N=3$. (- - ) Simulated time progress curves of $X_{3}$ $X_{6}$ and $X_{9}$ obtained by numerical integration of the set of differential equations (B1). 
Table 2. Values of $g(j)(j=3,6,9)$ and their standard errors corresponding to the approached analytical equations for $\left[X_{3}\right],\left[X_{6}\right]$ and $\left[X_{9}\right]$ in an open tricyclic cascade.

Cases 1, 2, 3 and 4 correspond to those in Figs. 1, 2, 3 and 4, respectively, but using a reaction time $T$ (equal to $t_{0}$ ) of $100 \mathrm{~s}$ (instead of the $40 \mathrm{~s}$ in the figures) at which the steady state is largely reached in the four cases. In case 1 (inset) the reaction time, $T$, used was $8 \mathrm{~s}$ (as in inset of Fig. 1) at which the $\left[\mathrm{Y}_{2}\right]$ and $\left[\mathrm{Y}_{3}\right]$ values do not considerably differ from their initial values $\left[\mathrm{Y}_{2}\right]_{0}$ and $\left[\mathrm{Y}_{3}\right]_{0}$ so that our analysis could be used. The $\mathrm{g}(\mathrm{j})$ values were obtained from the values given by the analytical approach at any time in comparison with that from the corresponding simulated curve at the same time, according to Eqn. (84). The values of time points, $Q$, in each simulation are also indicated in the last column. Note that if we fix the limit parameter G as 0.05 , then the approach is good in the reaction time considered (100 s) for $\mathrm{X}_{3}$ in the four cases, for $X_{6}$ in cases 2, 3 and 4 and for $X_{9}$ in cases 3 and 4. If in case 1 we consider a reaction time of $8 \mathrm{~s}$ (inset) then the approach is good for $\mathrm{X}_{3}, \mathrm{X}_{6}$ and $\mathrm{X}_{9}$.

\begin{tabular}{lllll}
\hline Case & $\mathrm{g}(3)$ & $\mathrm{g}(6)$ & $\mathrm{g}(9)$ & $\mathrm{Q}$ \\
\hline 1 & $8.3487 \times 10^{-6} \pm 9.1207 \times 10^{-8}$ & $0.0891 \pm 2.9547 \times 10^{-4}$ & $0.5497 \pm 2.2356 \times 10^{-3}$ & 11498 \\
1 (inset) & $1.4602 \times 10^{-5} \pm 1.5750 \times 10^{-7}$ & $0.0124 \pm 1.5739 \times 10^{-4}$ & $0.0292 \pm 4.4240 \times 10^{-4}$ & 3456 \\
2 & $1.6397 \times 10^{-6} \pm 1.8509 \times 10^{-8}$ & $0.0183 \pm 5.6544 \times 10^{-5}$ & $0.1130 \pm 4.2904 \times 10^{-4}$ & 10999 \\
3 & $8.3785 \times 10^{-8} \pm 9.3858 \times 10^{-10}$ & $9.1583 \times 10^{-4} \pm 2.8180 \times 10^{-6}$ & $5.6338 \times 10^{-3} \pm 2.1416 \times 10^{-5}$ & 10999 \\
4 & $1.7063 \times 10^{-6} \pm 1.8840 \times 10^{-8}$ & $0.0182 \pm 5.7883 \times 10^{-5}$ & $0.1117 \pm 4.3420 \times 10^{-4}$ & 11246 \\
\hline
\end{tabular}

$(j=2,3, \ldots, N)$ reaches the final concentration $\left[Y_{j}\right]_{s s}$ from its corresponding initial concentration $\left[Y_{j}\right]_{0}$ (note that $\left.\left[Y_{j}\right]_{s s}<\left[Y_{j}\right]_{0}\right)$. Thus, in each $j-t h(j=2,3, \ldots, N)$ cycle the limit of applicability of our results is that $\left[\mathrm{Y}_{\mathrm{j}}\right]_{\mathrm{ss}} /\left[\mathrm{Y}_{\mathrm{j}}\right]_{0}$ $\geq 1-G(j=2,3, \ldots, N)$ which is a more detailed version of Eqn. (80). In the $j$-th cycle $(j=2,3, \ldots N-1)$ the quotient $\left[\mathrm{Y}_{\mathrm{j}}\right]_{\mathrm{Ss}} /\left[\mathrm{Y}_{\mathrm{j}}\right]_{0}$ is less than in the next one, i.e. $\left[\mathrm{Y}_{\mathrm{j}}\right]_{\mathrm{ss}} /\left[\mathrm{Y}_{\mathrm{j}}\right]_{0}$ $<\left[\mathrm{Y}_{\mathrm{j}+1}\right]_{\mathrm{ss}} /\left[\mathrm{Y}_{\mathrm{j}+1}\right]_{0}(\mathrm{j}=2,3, \ldots, \mathrm{N}-1)$ so that the accuracy of our results diminishes from a cycle to the next one. Nevertheless, it can happen either that the condition of approximate constancy of $\left[Y_{j}\right]$ is observed in all of the cycles or that from a certain cycle our results can no longer be applied. Below, after defining the parameter in Eqn. (84), we suggest an unequivocal quantitative procedure to stabilise the limits of applicability of the postulated model.

We suggest the estimation of an upper value of $g(j)$ under which the approached equations for $\left[X_{j}\right] \quad[j=1,2, \ldots w(j)]$ are acceptable in the reaction time $T$, from which this approximation is less and less accurate, i.e., we introduce a limit parameter. We accept that a difference between $\left[Y_{j}\right]_{0}$ and $\left[Y_{j}\right]_{s s}$ less than or equal to (1-G) $\left[Y_{j}\right]_{0}$ means a good approximation and allows us to consider the analytical kinetic equations acceptable. We now assume the definition of $g(j)$ given in the example of tricyclic cascades to any other multicyclic cascade and moreover we apply this definition to the species $Y_{j} \quad(j=2,3, \ldots, N)$ for which we only need to replace $X_{j}$ by $Y_{j}$ in the definition [Eqn. (84)] and take into account that now $j=1,2, \ldots, N$. The differences $r_{j, k}$ and $r_{s, k}$ will be always positive and less than $G\left[Y_{j}\right]_{0}$ [note that the analytical equation for $\left[Y_{j}\right]$ in our analysis is given by $\left[Y_{j}\right]$ $\left.\approx[\mathrm{Y}]_{0}(\mathrm{j}=2,3, \ldots, \mathrm{N})\right]$. Obviously, at $t=0$ this difference is zero and it increases until the value at the steady state is reached, i.e. this difference remains less than $\mathrm{G}\left[\mathrm{Y}_{\mathrm{j}}\right]_{0}$ at any reaction time. Let us now consider the following hypothetical, non-real situation: at any reaction time $t_{1}, t_{2}, \ldots . t_{\mathrm{Q}}\left(t_{\mathrm{Q}}\right.$ is the reaction time $\left.T\right)$ the above differences are equal to $G\left[Y_{j}\right]_{0}$. Then, the corresponding $g(j)$ for $Y_{j}$ will be $G$ according to Eqn. (84), which surely is much higher than the true value $g(j)$ for $Y_{j^{\prime}}$ if the true values of the differences were used. But these hypothetical differences, $G\left[Y_{j}\right]_{0}$, between $\left[Y_{j}\right]_{0}$ and $\left[Y_{j}\right]$ would be acceptable. Thus, $g(j)$ $=G$ for the species $Y_{j}$ is acceptable as a border parameter for the accuracy of the theoretical progress curve of $\left[Y_{j}\right]$ in comparison to its experimental (simulated) progress curve. We suggest taking this same arbitrary $g(j)$ upper value, $G$, for all of the different species $X_{j}[j=1,2,3, \ldots w(j)]$ involved in order to know, in each case, the goodness of our analysis.

In Table 2 we give examples for a possible use of this upper value of $g(j)$, the limit parameter $\mathrm{G}$, in order to know the goodness of the approached solutions in the case of a tricyclic cascade. Note that if we fix the limit parameter $G$ as 0.05 , the approach is good in the reaction time considered (100 s) for $X_{3}$ in the four cases, for $X_{6}$ in cases 2, 3 and 4 and for $X_{9}$ in cases 3 and 4 . If we consider in case 1 a reaction time of $8 \mathrm{~s}$ then the approach is good in this time for $X_{3}, X_{6}$ and $X_{9}$. Graphically this degree of accuracy can be observed in Figs. 1-4.

\section{Analytic value of the presented work}

Apart from the considerations made in the Introduction section about the advantages of having transient phase equations of multicyclic enzyme cascades and their biological importance, they have, in our opinion, the following additional advantages:

(a) Metabolic control analysis (MCA) as proposed by Kacser and Burns (1973) and Heinrich and Rapoport (1974) and most other contributions in this field are limited to the steady state. The transient phase equations obtained here, giving the instantaneous concentration of the species involved, allow one to extend the MCA to study the effect of parameters on different variables of enzyme cascades. The basic definitions and relationships to analyse some control features of the instantaneous values of meta- 
bolic concentrations and fluxes were developed by Acerenza et al. (1989).

(b) From the equations derived here, other simpler ones, with less exponential terms, can be obtained by assuming that one or more of the reversible steps corresponding to the binding of the converter enzymes to the convertible enzymes are in rapid equilibrium, analogously as already done by Varón and Havsteen (1990) for the transient phase equations of monocyclic enzyme cascades.

\section{CONCLUDING REMARKS}

All of the objectives presented in the Introduction section have been accomplished. Apart from the intrinsic value of knowing the time kinetic behaviour of any of the species involved in an open multicyclic enzyme cascade, the presented kinetic analysis can be the basis of future contributions regarding open multicyclic enzyme cascades which require the knowledge of their time course equations (e.g. evaluation of the time needed to reach the steady state, suggestion of kinetic data analysis, etc.), analogously as that already carried out for open bicyclic cascades (Varon et al., 1994a). Likewise, the steady state kinetics of these cascades could be compared with those steady state results obtained by other authors under other assumptions.

The role of multicyclic interconvertible enzyme cascades (e.g. mitogen- or messenger-activated, or extracellular signal-regulated protein kinase cascades) in the regulation of basic and critical biological functions such as cell growth and division (Ballif \& Blenis, 2001; Santen et al., 2002; Bardwell et al., 2003; Bardwell, 2004), changes of volume (Hamish \& Christine, 2003; Yakar et al., 2003) and compartmentization (Labrecque et al., 2003) is the topic of a number of current contributions. The paper presented here may contribute to a better knowledge of the kinetic aspects of these features.

\section{Acknowledgements}

This work was partially supported by grants BQU2002-01960 of the Dirección General de Investigación (DGI) and GC-02-032 Junta de Comunidades de Castilla-La Mancha (Spain).

\section{REFERENCES}

Abramowitz M, Stegun IA, eds (1972) Solutions of Quartic Equations. In Handbook of Mathematical Functions with Formulas Graphs and Mathematical Tables; pp 17-18. Dover, New York.

Acerenza L, Sauro HM, Kacser H (1989) Control analysis of time-dependent metabolic systems. J Theor Biol 137: 423-444.
Ballif BA, Blenis J (2001) Molecular mechanisms mediating mammalian mitogen-activated protein kinase (MAPK) kinase (MEK)-MAPK cell survival signals. Cell Growth Differ 12: 397-408.

Bardwell L (2004) A walk-through of the yeast mating pheromone response pathway. Peptides 25: 1465-1476.

Bardwell AJ, Abdollahi M, Bardwell L (2003) Docking sites on mitogen-activated protein kinase (MAPK) kinases MAPK phosphatases and the Elk-1 transcription factor compete for MAPK binding and are crucial for enzyme activity. Biochem J 370: 1077-1085.

Beyer WH (1987) CRC Standard Mathematical Tables. 28th edn CRC Press Boca Raton FL.

Birkhoff G, Mac Lane S (1996) A survey of Modern Algebra. 5th edn. pp 107-108. Wiley, New York.

Boyer CB, Merzbach UC (1991) History of Mathematics. 2nd edn pp 283-287. Wiley, New York.

Burden R, Faires J (1985) Numerical Analysis. PWS, Boston.

Cárdenas ML, Cornish-Bowden A (1989) Characteristics necessary for an interconvertible enzyme cascade to generate a highly sensitive response to an effector. Biochem I 257: 339-345.

Cárdenas ML, Cornish-Bowden A (1990) Properties needed for the enzymes of an interconvertible cascade to generate a highly sensitive response. In Control of Metabolic Processes. Cornish-Bowden A, Cárdenas ML, eds, pp 195-208. Plenum Press, New York.

Cárdenas ML, Goldbeter A (1996) The glucose-induced switch between glycogen phosphorylase and glycogen synthase in the liver: outlines of a theoretical approach J Theor Biol 182: 421-426.

Chock PB, Stadtman ER (1977) Superiority of interconvertible enzyme cascades in metabolic regulation: analysis of multicyclic systems. Proc Natl Acad Sci USA 74: 2766-2770.

Chock PB, Stadtman ER (1980) Covalently interconvertible enzyme cascade systems. Methods Enzymol 64: 297-325.

Chock PB, Rhee SG, Stadtman ER (1980) Interconvertible enzyme cascades in cellular regulation. Annu Rev Biochem 49: 813-843.

Chock PB, Rhee SG, Stadtman ER (1990) Metabolic control by cyclic cascades mechanism: a study of $E$. coli glutamine synthetase. In Control of Metabolic Processes. Cornish-Bowden A, Cárdenas ML, eds, pp 183-194. Plenum Press, New York.

Cornish-Bowden A (1995) Fundamentals of Enzyme Kinetics; 2nd edn. Porland Press, Londres.

Cornish-Bowden A, Hofmeyr J-HS (1991) MetaModel: a program for modelling and control analysis of metabolic pathways on the IBM PC and compatibles. Comp Appl Biosci 7: 89-93

De Paula R, Azzariti de Pinho C, Terenzi HF, Bertolini MC (2002) Molecular and biochemical characterization of the Neurospora crassa glycogen synthase encoded by the gsn cDNA. Mol Gent Genomics 267: 241-253.

Edstrom RD, Meinke MH, Gurnack ME, Steinhorn DM, Yang X, Yang R, Evans DF (1990) Regulation of muscle glycogenolysis. In Control of Metabolic Processes. Cornish-Bowden A, Cárdenas ML, eds, pp 183-194. Plenum Press, New York.

Fehlberg E (1970) Classische Runge-Kutta Formeln vierter und niedrigerer Ordnung mit Schrittweitenkontrolle und ihre Anvendung auf Wärmeleitungs-probleme. Computing 6: 61-71.

Ferrell JE Jr, Machleder EM (1998) The biochemical basis of an all-or-none cell fate switch in Xenopus oocytes. Science 280: 895-898.

Gall D, Baus E, Dupont G (2000) Activation of liver glycogen phosphorylase by $\mathrm{Ca}^{2+}$ oscillations: a theoretical study. J Theor Biol 207: 445-454. 
Gálvez J, Varón R (1981) Transient phase kinetics of enzyme reactions. J Theor Biol 89: 1-17.

García-Sevilla F, Garrido del Solo C, Duggleby RG, GarcíaCánovas F, Peyró R, Varón-Castellanos R (2000) Use of a windows program for simulation of the progress curves of reactants and intermediates involved in enzyme-catalysed reactions. BioSystems 54: 151-164.

Goldbeter A, Koshland DE Jr (1987) Energy expenditure in the control of biochemical systems by covalent modification. J Biol Chem 262: 4460-4471.

Goldbeter A, Koshland DE Jr (1990) Zero-order ultrasensitivity in interconvertible enzyme systems. In Control of Metabolic Processes. Cornish-Bowden A, Cárdenas ML, eds, pp 173-182. Plenum Press, New York.

Goryanin I, Hodman TC, Selkov E (1999) Mathematical simulation and analysis of cellular metabolism and regulation. Bioinformatics 15: 449-758

Gustin MC, Albertyn J, Alexander M, Davenport K (1998) MAP kinase pathways in the yeast Saccharomyces cervisiae. Microbiol Mol Biol Rev 62: 1264-1300.

Hamish MF, Christine W (2003) Angiogenesis in the corpus luteum. Reprod Biol Endocrinol 1: 88-95.

Hanashiro I, Roach PJ (2002) Mutations of muscle glycogen synthase that disable activation by glucose 6-phosphate. Arch Biochem Biophys 397: 286-292.

Havsteen BH, García-Moreno M, Valero E, Manjabacas MC, Varón R (1993) The kinetics of the enzyme systems involving activation of zymogens. Bull Math Biol 55: $561-583$.

Hearon JZ (1963) Theorems on linear systems. Ann NY Acad Sci USA 108: 36-68.

Heinrich R, Rapoport TA (1974) Linear steady state treatment of enzymatic chains-general properties control and effector strength. Eur J Biochem 42: 89-95

Jacquez JA (1996) Compartmental Analysis in Biology and Medicine; 3rd edn. BioMedware, Ann Arbor.

Jiang P, Peliska JA, Ninfa AJ (1998) The regulation of Escherichia coli glutamine synthetase revisited: role of 2 ketoglutarate in the regulation of glutamine synthetase adenylylation state. Biochemistry 37: 12802-12810.

Kacser H, Burns JA (1973) The control of flux. Symp Soc Exp Biol 27: 65-104.

Kalir S, McClure J, Pabbaraju K, Southward C, Ronen M, Leibler S, Surette MG, Alon U (2001) Ordering genes in a flagella pathway by analysis of expression kinetics from living bacteria. Science 292: 2080-2083.

Krebs EG (1972) Protein kinases. Curr Top Cell Regul 5: 99-133.

Labrecque L, Royal I, Surprenant DS, Patterson C, Gingras D, Béliveau R (2003) Regulation of vascular endothelial growth factor receptor-2 activity by caveolin- 1 and plasma membrane cholesterol. Mol Biol Cell 14: 334347.

Lamb TD (1996) Gain and kinetics of activation in the Gprotein cascade of phototransduction. Proc Natl Acad Sci USA 93: 566-570.

Mendes P (1997) Biochemistry by numbers: simulation of biochemical pathways with Gepasi 3. Trends Biochem Sci 22: 361-363.

Mutalik VK, Shah P, Venkatesh KV (2003) Allosteric interactions and bifunctionality make the response of glutamine synthetase cascade system of Escherichia coli robust and ultrasensitive. J Biol Chem 278: 26327-26332.

Mutalik VK, Singh AP, Edwards JS, Venkatesh KV (2004) Robust global sensitivity in multiple enzyme cascade system explains how the downstream cascade structure may remain unaffected by cross-talk. FEBS Lett 558: 79-84.
Newsholme EA, Challiss RAJ, Crabtree B (1984) Substrate cycles: their role in improving sensitivity in metabolic control. Trends Biochem Sci 9: 277-280.

Ottaway JH (1988) Regulation of Enzyme Activity; p 4. IRL Press, Oxford.

Passonneau JV, Lowry OH (1978) In Principles of Enzymatic Analysis. Bergmeyer HU, ed, pp 86-87. Verlag Chemie Weinheim, New York

Passonneau JV, Lowry OH (1993) In Enzymatic Analysis: a Practical Guide. Passonneau JV, Lowry $\mathrm{OH}$, eds, pp 85-110. Humana Press, Totowa, New Jersey.

Pomerance M, Abduullah HB, Kamerji S, Corrèze C, Blondeau JP (2000) Thyroid-stimulating hormone and cyclic AMP activate p38 mitogen-activated protein kinase cascade. J Biol Chem 275: 40539-40546.

Rozi A, Jia Y (2003) A theoretical study of effects of cytosolic $\mathrm{Ca}^{2+}$ oscillations on activation of glycogen phosphorylase. Biophys Chem 106: 193-202.

Santen RJ, Song RX, McPherson R, Kumar R, Adam L, Jeng MH, Yue W (2002) The role of mitogen-activated protein (MAP) kinase in breast cancer. J Steroid Biochem Mol Biol 80: 239-256.

Sauro HM (1993) SCAMP: a general-purpose simulator and metabolic control analysis program. Comp Appl Biosci 9: 441-450.

Sauro HM (2000) JARNAC: a system for interactive metabolic analysis. In Animating the Cellular Map. Hofmeyr J-HS, Rohwer JM, Snoep JL, eds, pp 221-228. Stellenbosch University Press, Stellenbosch.

Schulz AR (1998) Control analysis of muscle glycogen metabolism. Arch Biochem Biophys 353: 172-180.

Shacter E, Chock PB, Rhee SG, Stadtman ER (1986) In The Enzymes; vol XVII, Boyer PD, Krebs EG, eds, pp 21-42. Academic Press, New York.

Smith DE (1994) A Source Book in Mathematics. Dover, New York.

Stadtman ER (1990) Discovery of glutamine synthetase cascade. Methods Enzymol 182: 793-809.

Stadtman ER (2001) The story of glutamine synthetase regulation. J Biol Chem 276: 44357-44364.

Stadtman ER, Chock PB (1977) Superiority of interconvertible enzyme cascades in metabolic regulation: analysis of monocyclic systems. Proc Nat Acad Sci USA 74: 2761-2765.

Stadtman ER, Chock PB (1979) Advantages of enzyme cascades in the regulation of key metabolic processes. In The Neurosciences Fourth Study Program. Schmidtt FO, ed, pp 801-817. M.I.T. Press, Cambridge.

Stadtman ER, Chock PB, Adler SP (1976) In Metabolic Interconversion of Enzymes. Shaltiel S, ed, pp 142-149. Springer-Verlag, New York.

Szedlacsek SE, Cárdenas ML, Cornish-Bowden A (1992) Response coefficients of interconvertible enzyme cascades towards effectors that act on one or both modifier enzymes. Eur J Biochem 204: 807-813.

Thattai M, van Oudenaarden A (2002) Attenuation of noise in ultrasensitive signaling cascades. Biophys J 82: 29432950.

Valero E, García-Carmona F (1996) Optimizing enzymatic cycling assays: spectrophotometric determination of pyruvate and L-lactate. Anal Biochem 239: 47-52.

Valero E, Varón R, García-Carmona F (1997) Mathematical model for the determination of enzyme activity based on enzymatic amplification by substrate cycling. Anal Chim Acta 346: 215-221.

Valero E, Varón R, García-Carmona F (2000) Kinetics of a self-amplifying substrate cycle: ADP-ATP cycling assay. Biochem J 350: 237-243.

Van den Steen P, Rudd PM, Dwek RA, Van Damme J, Opdenakker G (1998) Cytokine and protease glycosylation 
as a regulatory mechanism in inflammation and autoimmunity. Avd Exp Med Biol 435: 133-143.

Varón R, Havsteen BH (1990) Kinetics of the transient phase and steady-state of the monocyclic enzyme cascades. I Theor Biol 14: 397-413.

Varón R, Molina-Alarcón M, García-Moreno M, García-Sevilla F, Valero E (1994a) Kinetic analysis of the opened bicyclic enzyme cascades. Biol Chem Hoppe Seyler 375: 365-371.

Varón R, Havsteen BH, Molina-Alarcón M, Szedlasek SE, García-Moreno M, García-Cánovas F, (1994b) Kinetic analysis of reversible closed bicyclic enzyme cascades covering the whole course of the reaction. Int J Biochem 26: 787-797.
Varón R, Ruiz-Galea MM, Garrido del Solo C, García-Sevilla F, García-Moreno M, García-Cánovas F, Moya-García G, Havsteen BH (1999) Transient phase of enzyme reactions. Time course equations of the strict and the rapid equilibrium conditions and their computerized derivation. BioSystems 50: 99-126.

Weisstein EW (1995) QuarticEquation. From Math/WorldA Wolfram Web Resource. http:// mathworld.wolfram. com/QuarticEquation.html

Yakar I, Melamed R, Shakhar G, Shakhar K, Rosenne E, Abudarham N, Page G, Ben-Eliyahu S (2003) Prostaglandin $\mathrm{E}_{2}$ suppresses NK activity in vivo and promotes postoperative tumor metastasis in rats. Ann Surg Oncol 10: $469-479$. 